This PDF is a selection from an out-of-print volume from the National Bureau of Economic Research

Volume Title: The Rate and Direction of Inventive Activity: Economic and Social Factors

Volume Author/Editor: Universities-National Bureau Committee for Economic Research, Committee on Economic Growth of the Social Science Research Council

Volume Publisher: Princeton University Press

Volume ISBN: 0-87014-304-2

Volume URL: http://www.nber.org/books/univ62-1

Publication Date: 1962

Chapter Title: The Economics of Research and Development

Chapter Author: Jora R. Minasian

Chapter URL: http://www.nber.org/chapters/c2115

Chapter pages in book: (p. 93 - 142) 


\title{
The Economics of Research and Development
}

\author{
JORA R. MINASIAN \\ THE RAND CORPORATION
}

\section{Introduction}

THE PROBLEM AND THE SUMMARY OF RESULTS

THE contribution of productivity changes to economic growth has attracted much attention in recent years. Real income per capita in the United States roughly quadrupled from 1869-78 to 1944-53. Per capita inputs of labor and capital weighted by their relative contribution in the base period (the nineteen twenties) increased only by some 14 per cent. ${ }^{1}$ This suggests that there has been a substantial increase in the net national product that can not be explained by the increases in inputs, conventionally measured.

The rate of growth in productivity has neither been uniform over time nor the same for different industries. For example, although none of the industries studied by Kendrick ${ }^{2}$ experienced a decline in productivity over the long period from 1899 to 1953, there are several which show declines during subperiods. During approximately ten year subperiods the average annual rates of change in the productivity ratios of the thirty-three industries Kendrick studied range from $(-4$ per cent) to at least 9 per cent. The interindustry differences persist

Note: This paper is a reproduction, with minor omissions, of a Ph.D. dissertation, "The Economics of Research and Development," Department of Economics, University of Chicago, 1960.

This study was carried out while I was a member of the Econometrics Workshop at the University of Chicago, and was made possible by a grant from the Ford Foundation. I am indebted to many faculty members and students in the Department of Economics of the University of Chicago. I would like to single out for special thanks C. Christ, who directed my work, G. Stigler, M. Bailey, Y. Grunfeld, A. Harberger, and J. Rothenberg. I am grateful to $\mathrm{L}$. Sjaasted for his valuable editorial help.

I would also like to thank my wife, Diane, who not only helped directly in the preparation of the dissertation but enabled me to remain in the University at an earlier stage of my career at her expense.

The author bears the full responsibility for all the shortcomings of this paper. Neither the persons nor the organizations mentioned above necessarily agree with any of the statements made.

${ }^{1}$ Moses Abramovitz, Resource and Output Trends in the United States Since 1870, Occasional Paper 52, New York, National Bureau of Economic Research, 1956.

${ }^{2}$ John W. Kendrick, Productivity Trends: Capital and Labor, Occasional Paper 53, New York, NBER, 1956. 
for all subperiods. By comparison, the annual rate of change for the 1899-1953 period as a whole ranges from zero to 6 per cent.

Why do productivity changes differ among industries and over time? What are the factors leading to increased productivity?

This study advances the general hypothesis that productivity increases are associated with investment in the improvement of technology and the greater the expenditures for research and development the greater the rate of growth of productivity.

In principle, there are two ways of obtaining productivity increases: (1) economies of scale; and (2) either a change in the state of the arts and sciences - that is, improvement of the available technology-or utilization of better techniques which are already known. In the first category belong all the factors associated with change of scale and identified with movements along the cost curve. All possible factors that shift the production function (and thus the cost curve under constant prices and scale) fall in the second category.

We have empirical information which suggests that industrial organization (degree of competition) is correlated with growth in productivity. ${ }^{3}$ This is an important explanatory variable. However, its main contribution is the light it sheds on the question of the industrial organization most favorable to innovation and economic progress. Although there is disagreement on that question, there is general agreement among economists that innovation by the entrepreneur achieves technological change and increases productivity.

Economies of scale, industrial organization, and quality of the labor force are relevant variables which can account for some of the unexplained increase in net national product. However it is usually agreed that the greater portion of this increase has resulted from technological changes causing a substantial increase in productivity.

One of the main variables singled out by quite a few economists has been research and development activity carried out by the firm. Research and development represents investment in knowledge which in turn affects the technology which improves productivity. However our only knowledge of this process consists of vague theoretical postulates and hypotheses which have not been subjected to empirical tests, which is why this study came about.

In trying to fill this gap in our knowledge, I have undertaken an empirical analysis of the relationship between productivity increase

\footnotetext{
${ }^{3}$ George J. Stigler, "Industrial Organization and Economic Progress," Paper read at 25th Anniversary of the Social Science Research Building, University of Chicago.
} 
and research and development expenditures, and tested some alternative hypotheses. This is a cross-section study on the firm level. Eighteen firms in the chemical and allied products industry and five firms in the drug and pharmaceutical industry constitute the sample. The observed value of each variable for the cross-section study is based on the period 1947-57 because of lack of earlier data for most firms.

We can conclude from this study that, beyond a reasonable doubt, causality runs from research and development to productivity, and finally to profitability. With the possible exception of differential monopoly power (the test of its influence was not conclusive) no other factor tested was able to compete effectively with, or even to complement substantially, the relationships found between the above variables.

In the remainder of this section some conceptual problems are discussed. Next, we define our hypothesis and proceed to a discussion of our variables, measurements thereof, and sampling considerations. Finally, we test our main hypothesis, and consider alternative hypotheses of profitability, investment, economies of scale, and monopoly pricing. We also test for returns to research and development expenditures.

\section{SOME CONCEPTUAL PROBLEMS}

In principle we would like to have firms identical in all respects except the independent variables under consideration. The fewer and the weaker the influential variables which are not taken into account explicitly, the more reliable the results. The firms constituting our sample are not homogeneous with respect to scale or to diversification of production. I will consider a few broad conceptual difficulties at this point and introduce more specific ones as we progress.

\section{Crossing Industry Boundaries}

One of the reasons we must be cautious in generalizing the results of this study is our lack of knowledge about the cost of innovation. Does it cost the same amount to achieve an innovation which will result in a given percentage increase in productivity, regardless of the nature of production or the industry? Since we do not know the facts, I have analyzed firms in the two industries separately.

The external effects on the industry may not fall uniformly on all firms in the industry since the output mixes of the firms are different. 
To the extent that this happens, external effects will influence the results. Due to the difficulty of designing a meaningful test for differential external effects, we have not allowed for this influence; this must be borne in mind when interpreting the results.

\section{Scale}

Scale has three different connotations in this study:(1) scale signifying economies of scale in production, (2) scale signifying economies of scale to research and development, and (3) scale in terms of correlation where both dependent and independent variables are positively correlated with scale.

1. I have already mentioned the case of economies of scale and have recognized it to be a possibly important variable.

2. If we admit the possibility that the research and development expenditure required to reduce average cost by $\mathrm{X}$ per cent is independent of output, then the returns from research and development to the industry will increase with industry output. However, for the firm, returns to research and development will not increase as its relative share of industry output increases, if it can monopolize the information and sell it on a perfect market.

3. Scale in the third role is analogous to the trend in time series data. It can be handled either by including a scale variable (when using absolute research and development expenditures) in the function, or by deflating research and development by a suitable size variable.

The scale of operation is not only a simple question of size; it is also positively correlated with the number of products produced. That is to say, firms are diversified to different extents. Therefore, in most cases scale also represents diversification, to the discussion of which we now turn.

\section{Diversification}

The varying degree of diversification among firms raises two important problems. The first concerns the construction of index numbers. I will deal with this and other index number problems later. However, it should be noted in passing that the greater the degree of diversification the more appropriate become Bureau of Labor Statistics indexes of wholesale prices and wage rates. The second prob- 
lem is whether there are research and development economies resulting from diversification of output. There is a strong belief that a dollar spent on research and development yields a higher return, the greater the degree of diversification of output. One may think of four reasons for such a belief:

1. Unanticipated findings will be more readily recognized and therefore utilized. This proposition sounds plausible but there is no way to test it. However, one would expect random findings of the nature postulated to be a small portion of all findings and, also, the more diversified firms will probably have more independent projects with less effective communication among researchers. However, if diversification of research and development increases with diversification of output, and specialization of researchers goes up with output, the larger firms may have the advantages associated with specialization of function.

2. A particular finding may require a specialized test which may not be available to a less diversified concern. The lack of specialized services within the firm might be a deterrent but obviously not a completely effective one, in view of the rise of independent industrial laboratories during recent decades, which will supply these services at a price.

3. The finding may not be in line with the concern's existing activities, hence it may not be used. If the finding is worthwhile, there are two alternatives available to the firm. One is to produce the product or utilize the new process in its own production. The other is to sell or rent the finding. The firm is equally happy with both choices if it can patent its finding and sell it in a perfect market.

4. Knowledge created may be used in the production of more than one product. This requires a note of clarification about the ambiguities involved in the term diversification. There are two kinds of diversification which are fundamentally different for the purposes of this study: diversification in kinds of products among which knowledge of production is transferable; and that in which it is not transferable. When we speak of economies of diversification, we should mean diversification of the transferable kind. Then, it is not at all clear which way the economies of diversification run. If diversification is taken to be the consequence of past research, then the economies of diversification are nothing but the result of the knowledge thus accumulated, a simple case of return to past research and development expenditures. However, if one chooses the second definition of diversification, it is not 
clear to the writer why and how economies of diversification will come into the picture..$^{4}$

These propositions will not be tested directly. The above discussion indicates the difficulty of finding a variable which can be used in testing them. However, if scale of operation is positively correlated with diversification, a test for scale will be a partial test of the diversification hypotheses.

\section{The Hypothesis}

The production function of a firm summarizes the technological conditions under which the firm operates and shows the maximum quantity of output that can be produced with given quantities of each of the factors of production that are used. Ordinarily, output, $X$, is related to inputs of labor, $L$, and capital, $K$, in a production function of the form

$$
X=f(L, K)
$$

which is often assumed to be homogeneous of the first degree. All variables are measured as dollar magnitudes deflated by price indexes. The derivation of such a function is especially complicated when the economy is characterized as progressive over time. The difficulties that arise may be classified in two categories:

1. The inputs, even adjusted to a constant dollar basis, are not homogeneous over time because of quality changes in labor and capital.

2. Given the quantities of inputs, free of the problem in 1 above, varying quantities of output can be produced depending on the knowledge of the arts and sciences available and used in the process of production - that is, the existing technology utilized. However, technological change may alter the desired quality of inputs as well as the combination of inputs and the scale of operation.

One can use more relevant indexes in dealing with the first problem, although we are still short of correct indexes. On the second problem,

\footnotetext{
${ }^{4}$ Here I am abstracting from the case in which the product whose price is lower now, because of greater productivity, may be used in the production of other products thus lowering the prices of the latter and increasing their sale. Growth in the output of these other products may give rise to economies of scale.

${ }^{5}$ Diversification of the second kind creates a measurement problem. If the proportion of research and development funds allocated to each product differs from the proportion of other inputs, then an average research and development measure may not accurately describe the intensity of the research and development activity.
} 
neither the theory nor the empirical knowledge is rich. The problem of measurement aside, the production function is characterized by under-specification of inputs, i.e. the impact of technological changes is not explicitly incorporated in the process of estimation. Thus the conventional approach, i.e. using equation 1 with no explicit allowance for changes in technology, tends to correlate the output with wrongly identified inputs. This can cause biased estimates of coefficients of the specified variables, namely, labor and capital.

The conventional production function ought to be rewritten. In general, we may express the production function as

$$
X_{t}=f\left(L_{t}, K_{t}, P_{t}\right)
$$

where $X_{t}, L_{t}, K_{t}$, and $P_{t}$ represent output, labor, capital, and productivity (a parameter shifting the production function), respectively, at time, $t$. Furthermore, if we assume the case of neutral change in technology, we can rewrite 2 as

$$
X_{t}=P_{t} f\left(L_{t}, K_{t}\right)
$$

Ample attention has been focussed on the role of the entrepreneur in allocating resources under competitive and stationary conditions in economic literature. However, in a changing economy another important task should be assumed, namely, the investment in knowledge to obtain improved or new technology: Thus, in a changing economy the great economic force of innovation arises from a decision variable of the firm. It is an economic decision, so we are interested in knowing its costs and returns. Its costs may be thought of as expenditures on research and development; its returns as some part of the increased output unexplained by the conventional production function. The role of technology is to change the parameters of the conventional production function, and expenditures on research and development may be viewed as the cost of making such changes. Our equation 3 expresses this process in a manner that enables us to approximate these changes with a single variable.

In equilibrium, the marginal return ex ante on a dollar spent on labor, capital, or research and development should be the same. But the only data we have in this study are the annual expenditures on research and development and indexes of productivity (obtained using equation 3). We can do no more than estimate the gross effect of the one on the other. We cannot identify any particular development project with any subsequent growth in productivity. Nor even 
can we say which particular experiments were successful and which were not. Nevertheless, we know that a firm, under the dictates of rational behavior, will seek to maximize the present value of its expected return. Therefore, under a changing economy the firm will invest in research and developmentin order to create new products and processes and to improve the old products so that it may compete better in the market, stay in business and reap a monopoly profit, or both.

An interesting implication is that the research and development program of a firm reflects the effort or costs of the firm in the direction of obtaining efficiency. Logically, therefore, one would expect that a change in the productivity of the firm would be somehow related to its research and development activities. Consequently, we propose the general hypothesis: The greater the research and development expenditures, measured in several ways to be described below, the greater is the subsequent rate of growth in the productivity of a firm.

For the reasons outlined, research and development expenditures will be viewed as a variable shifting the production function over time. It is not clear how this variable should be measured in a sample where firms are neither equally diversified in kind and number of products produced, nor equal in scale of operation. These differences create great difficulties in determining an appropriate measure of research and development. If, in fact, research and development has the postulated effects, the measure thereof must have the power of discriminating among firms with respect to differences in productivity, without reflecting other influences which may be hidden in the statistic.

One has to ask whether the cost of a given percentage increase in productivity is the same for different products and different scales of output. If it is, then, given demand conditions, the return to research and development expenditure is higher the larger the total value of the product. ${ }^{6}$ Furthermore, as stated in the introduction, the problem of diversification enters into the picture. I have not tested for the effect of diversification for lack of a meaningful measure of that variable. In this study research and development measures are deflated by two alternative size-of-firm variables to standardize the firms for the effect of scale. The scale measures utilized are (1) a weighted average of real labor and capital inputs, the weights being determined by Euler's theorem (discussed below); and (2) the real gross stock of plant and equipment.

${ }^{6}$ This assumes the technology can be monopolized by the developing firm. 
I have chosen these scale variables because research and development expenditure is expected to shift the production function and, therefore, its ratio to inputs going directly into the production function is important. ${ }^{7}$ Alternatively, looking at research and development as an input of production, one can see the ratio as an analytical measure to be interpreted by the law of variable proportions. It should be noted that the above measures do correct for the diversification effect if scale is a positive function of diversification (with perfect correlation). But they do not correct for differences in the cost of the given technology if there are differential innovation costs depending on the type and kind of product.

Finally, it is certain that the effect of research and development takes place with a lag. In fact research and development is a good example of a distributed lag. In the study of cross-sectional differences among firms with respect to the rate of change in productivity, we are interested in finding a measure of research and development which reflects the intensity of this activity. Because of the short period for which data are available and other data deficiencies (discussed in detail further on), I have chosen two simple measures of research and development activity for each firm. One measure is an average of recent research and development expenditures divided by a weighted average of recent inputs of labor and capital. The other is the same numerator divided by an average of recent figures for real gross plant and equipment. More specifically the following estimation methods were used:

$$
R_{i}=\frac{\sum_{t=47}^{56}(\mathrm{R} . \mathrm{D} .)_{t}}{\sum_{t=47}^{56}\left(L^{a} K^{1-{ }^{a}}\right)_{t}}
$$

${ }^{7}$ Renting or purchasing new technologies will also shift the production function. Royalties paid by the firm indicate the extent of this influence and will be tested in the section dealing with empirical results. 
where R.D., $L$, and $K$, represent real research and development expenditure, labor, and the real gross stock of plant and equipment, respectively.

Two comments on these measures are appropriate. First, if the time-shape or the lag of research and development has not changed, measures 4 and 5 are fairly good estimates of what we want since a relatively long span of time is used. On the other hand, if the time shape has changed, then clearly a distributed lag is far superior to these measures. Second, these measures will not distinguish between opposing tendencies if research and development expenditures increase over time and then decrease over time, so that the average for the period remains the same. However, both $R_{i}$ and $R_{k}$ are positively correlated with time for all firms in this period.

Equations 4 and 5 will define the intensity of research and development activity for the firms and one of them will constitute an important independent variable in our analysis.

The dependent variable in this study is the rate of growth of productivity. This choice introduces a few methodological advantages. First of all, one of the most troublesome questions, that of labor quality, has been defined away. This problem arises because of our inability to take into account the increase in the value of the labor hour over time which is assumed to result from rising standards of education and health. It does not bother us since we are interested in explaining the differences in the rate of growth in productivity among firms in the same industry. There is no reason to believe that the consequences of the increased quality of the labor force will differ among industry members. Thus whatever the effect of this change may be, it is expected to be uniform for all the firms. Second, this measure depends on the experience of a firm over the period and not at a particular point in time; thus the role of fortuitous and random elements is minimized.

The rate of growth in productivity for each firm will be estimated by the following method.

Assume a production function homogeneous of the first degree in labor and capital and the case of neutral change in technology over time. Furthermore, assume this function to be of the Cobb-Douglas form. Thus we have

$$
X_{t}=P_{t} L_{t}^{a} K_{t}^{1-a}
$$


where $X_{t}, P_{t}, L_{t}$, and $K_{t}$ represent value added (or output), productivity, labor, and capital, respectively, in time, $t$. Therefore,

$$
P_{t}=\frac{X_{t}}{L_{l}^{a} K_{t}^{1-a}}
$$

The change in productivity between two periods can be obtained by

$$
\frac{P_{t}}{P_{t-1}}=\frac{X_{t} L_{t-1}^{a} K_{t-1}^{1-a}}{X_{t-1} L_{t}^{a} K_{t}^{1-a}}
$$

The rate of growth in productivity for an individual firm will be estimated by regressing $\log _{e} \frac{P_{t}}{P_{o}}$ on time. That is:

$$
\frac{P_{t}}{P_{o}}=C e^{r t}
$$

where $r$ is the slope of the regression line and the rate of growth of productivity. $P_{o}$ is the value of $P$ at the beginning of the period.

We can compute $a$ by using Euler's theorem which states that if the production function is homogeneous of the first degree and the factors of production are paid their marginal products, the total payments will exhaust the product. Thus from value added, $a$ will be obtained by the share of labor: ${ }^{8}$

$$
\begin{aligned}
a= & \frac{\text { Wage bill }}{\text { wage bill }+ \text { profits before taxes (adjusted by other }} \\
& \text { income or expense not related to production, i.e., } \\
& \text { dividends received or paid) + interest paid }+ \\
& \text { depreciation. }
\end{aligned}
$$

This assumes that the firms are in equilibrium every year. Of course, this may not be true. However, $a$ is taken as the average for the sample

${ }^{8}$ This formulation assumes that taxes on profits are paid by the owner(s) of the firm, so the contribution of capital to production is gross of taxes. An alternative formulation may be to assume that benefits derived from taxes are shared by labor and capital according to their relative shares of input. On this view point, the weights may be determined by using value added net of taxes in the denominator of equation (10), and then using value added gross of taxes in the numerator of equation (6). We will test the research and development hypothesis using rate of growth in productivity and the weights obtained by both formulations. We will find that the results of the study do not depend on the choice of the formulation. 
period. For the firms observed, there is no systematic tendency or trend in the annual values of $a$ over the period. ${ }^{9}$

We will obtain the rate of growth in productivity for each firm from 9 and correlate these rates cross-sectionally with the measures of research and development obtained from 4 and 5 above. In the next section the sample, the data, and the measurements of the variables will be discussed.

\section{The Sample, the Nature of Data, and the Estimation of Variables}

\section{THE SAMPLE}

Ultimately we will concern ourselves with interpreting our results and deriving statistical inferences. Therefore it is important to know the process by which the sample was obtained.

It is to be mentioned that the general and the main hypothesis was formed before data became available. The first survey of company annual reports revealed that the greatest likelihood of success in finding research and development data was with chemical and pharmaceutical firms. Realizing the dangers of crossing industry lines, I concentrated on firms classified within these two industries.

Moody's Industrial Manual was consulted. For none of the firms investigated were research and development expenditures shown. A second item which seemed equally difficult to obtain was wage and salary expenditures. To reduce the data problem, a sample of $85 \mathrm{firms}$ was chosen for investigation on the basis of the completeness of the accounting information published in Moody's. Out of 85 firms contacted by letter, 19 supplied all the data requested, 6 supplied all but research and development expenditures, 13 all but research and development and wage and salary expenditures, 7 supplied all data but for a shorter period of time than 1947-57, 12 supplied all but wages and salaries, and 28 did not reply.

The method of choosing the 85 firms and the pattern of response make our sample strictly a nonrandom one. Instead of hypothesizing inconclusively about the motives or conditions which generated this sample, I would like to emphasize that the results of this study should be interpreted strictly as applicable to the sample.

\footnotetext{
${ }^{2}$ The assumption of constant returns to scale is made as a way out of measurement problems rather than as an economic principle. This assumption will be tested in the section on empirical results.
} 
THE DATA

As we are interested in some physical measure of productivity, we need to eliminate price changes. We want to obtain real magnitudes of output, value added, labor, capital, and research and development expenditures and to use them in the manner described in equations 4 , 5 , and 9 above. The dollar values of these variables are deflated as described below.

\section{Real Output and Real Value Added}

Sales adjusted by the changes in the beginning and ending inventories of finished products equals output. We use the denominator of equation 10 as an approximation of value added. A better estimate could have been obtained if data on raw materials consumed had been available.

A growth measure using value added reflects the contribution of labor and capital better than one using gross output (including materials' value) because raw materials may not have remained a constant proportion of the output over time. Also, to the extent that firms purchase semifinished goods to be processed and sold, i.e., vertical integration, the gross output figures distort the picture. The proportion of output which comprises this type of good, its behavior over time, its magnitude among firms, and the extent of processing may differ and thus output may not reflect the true contribution of labor and capital inputs. However, value added will be immune to these variations.

The general problems of index number construction are well known and need not be mentioned here. However, two specific aspects of the subject should be dealt with since their importance is magnified in this study. In the first place we are studying the production function of the firms, so we need prices at the manufacturers' level. Second, since the study is carried out on the firm level, our choice of a price index should be such that a set of varying weights assigned to different products will approximately reflect the product mix produced by the firms. ${ }^{10}$

The first criterion above necessitates the use of a wholesale price index. Therefore, the BLS wholesale price indexes of the chemical

\footnotetext{
${ }^{10}$ New products must be entered into the product mix, but choice of the relevant price creates a problem. As the product becomes well known the price may rise because of increased demand, but if monopoly power over a new product falls over time, the price will fall. These problems will be discussed in more detail subsequently.
} 
industry broken into subcategories were investigated. As there are substantial differences in the pattern of change in the wholesale price indexes of these subcategories, it was imperative to match the output mix of the companies with the appropriate subclass price indexes.

Data on the output mix of the firms by broad categories of products were available only for 1954-57. Except for five pharmaceutical firms, the relative output weights were determined on this basis and price indexes computed for each firm. Both output and value added figures were then deflated by these price indexes, since no information on materials consumed and the prices thereof was available to be used in the construction of value added price indexes.

The drug and pharmaceutical wholesale price index used was derived from two BLS wholesale price indexes: one for drugs, pharmaceuticals, and cosmetics and one for cosmetics alone. The weights used by the BLS in combining drugs and pharmaceuticals with cosmetics were $3 / 4$ and $1 / 4$, respectively, in both 1953 and 1957. Using the following relation, the price index for drugs and pharmaceuticals was derived:

Price index of drugs and pharmaceuticals, and cosmetics $=3 / 4$ (price index of drugs and pharmaceuticals) $+1 / 4$ (price index of cosmetics)

then,

Price index of drugs and pharmaceuticals $=4 / 3$ (price index of drugs, pharmaceuticals, and cosmetics) - 1/4 (price index of cosmetics).

This wholesale price index was used to deflate both the output and the value added of the pharmaceutical firms.

\section{Labor}

Total wages, salaries, and other employee compensations such as vacation time, sick leave, insurance, retirement funds, etc., are taken as the contribution of labor to production. We would have liked to exclude that part of the wage bill which is attributable to research and development activity; however, this breakdown was not available. This is not important as research and development expenditures are only from 1 to 6 per cent of total wage payments. In equation 9 labor is weighted at roughly 60 per cent of total inputs. Aproximately 70 per cent of the total research and development expenditures are wages and salaries and the rest, materials costs and depreciation on laboratories. Thus the relative effect of being unable to exclude research and development wages and salaries is very small. 
The firm's wage rate was obtained by weighting the BLS index of the average hourly earnings of subclasses in the total chemical, drug, and pharmaceutical industries by the same weights used in construction of the price indexes. The total wage bill is deflated by these wage rate indexes.

Although this deflation does not correct for changes in the productivity of the labor force over time, it will correct for differences existing at a point of time, if the relative wage rates represent the relative service inputs.

\section{Plant and Equipment}

We need service flows of capital for our production function but these data are not available. One may think of three alternative measures of service flow of capital: (1) depreciation, (2) stock of capital net of depreciation, and (3) gross stock of capital. Measures 1 and 2 are clearly affected by tax rules and, above all, are the result of an accounting method which is, or may be, completely arbitrary. This criticism does not apply to measure 3. However, there are a number of other difficulties associated with this concept. First, if the durability of plant and equipment changes over time, the service flow of gross capital stock will vary with time, since for a given per-annum service flow the price of the capital good should be a positive function of durability, ceteris paribus. Second, the per-annum service flow of a given stock of capital will vary depending on how intensively the capital is used. Since the period of our study is relatively short (194757 ), we can realistically assume that changes in durability are minor. I have no conclusive evidence on the second problem.

I will assume that there is a constant relationship between service flows and the stock of capital. More specifically, my choice assumes that changes in the durability of plant and equipment, the interest rate, ${ }^{11}$ and the hours "worked" by the capital per week did not affect the relationship during so short a period as 1947-57.

I have chosen gross plant and equipment as a measure of capital for two reasons. (1) Gross stock was chosen under the assumption that as long as the capital was not retired the service flow was maintained via repairs and maintenance. It is felt that the error involved in this

\footnotetext{
${ }^{11}$ The interest rate is relevant to the extent that changes in it, while leaving the flow unaltered, will alter my measure of the stock of capital, which is in value terms. While flows only are relevant to my problem, we measure those flows by the value of the stock, hence we must worry about the interest rate.
} 
procedure is much less than that likely to occur in trying to correct the service flow by some arbitrary percentage representing presumably lesser productivity due to obsolescence, breakdowns, etc. (2) Choice of plant and equipment instead of a concept inclusive of land, minerals, and other current assets, i.e. inventories, cash, etc., is based on the possibility that some firms hold such properties for long-run considerations which are not necessarily relevant to current production. ${ }^{12}$ In summary, then, the gross plant and equipment at the year end will represent the capital entering into the production function in that year. The method of construction of this variable is given below.

Data on gross plant and equipment at the beginning of the year, gross investment, and gross retirement, broken down by categories and types, are given in the Annual Reports-Form 10-K, submitted to the Securities and Exchange Commission by publicly owned firms. These reports date back to 1934 when the Securities Exchange Act was passed. In order to construct a continuous series, we need an estimate of the stock of capital in 1934.

We have estimates of gross plant and equipment, in money terms, for January 1, 1934. The gross national product implicit deflators for new construction and durable equipment change but little during 1919-29, with the exception of one or two years. Therefore, the 1929 indexes are not bad indexes for the preceding decade. I have deflated gross plant and equipment at the beginning of 1934 by the 1929 price indexes for new construction and durable equipment, respectively. ${ }^{13}$ Each year's gross additions to plant and equipment have been deflated by the price index of that year and added successively to the stock of real plant and equipment of the initial year. It has been assumed that generally the retired capital was the oldest. Therefore, the 1929 GNP implicit deflators were used to deflate the retirements of the years 1934-46. Retirements of 1947-57 were assumed to have been purchased during 1940-47. So each of the two price indexes of this latter period were weighted by the relevant gross private domestic

\footnotetext{
${ }^{12}$ It may, however, be argued that total gross capital is the more relevant concept, since (1) total resources available determine productivity in a given year, and (2) long-run considerations are important because we are interested in the rate of growth in productivity. It will be found later that the results of the study do not depend on the particular choice of a capital concept.

${ }^{13}$ Changes in book values of fixed assets of a few firms for which data were available for 1929-33 were investigated. Four firms had positive changes ranging approximately from 4 to 10 per cent and three firms negative changes of 5 to 20 per cent of fixed assets in 1934. Most of the positive change took place in 1930.
} 
investments for 1940-47 to obtain an average deflator. This weighted average deflator was then used to deflate retirements of $1947-57 . .^{14}$

So long as the GNP implicit price deflator reflects the technological changes in capital, that is, the quality changes, we have corrected for the changes in the efficiency of capital. But to the extent that it does not reflect these changes over time and quality has improved, our capital stock is under estimated in recent years. The effect of this is especially important if the capital of different firms has undergone different rates of technological improvement over time and/or the magnitude of capital investment has varied among firms.

\section{Research and Development Expenditures}

Research and development expenditures are deflated by the GNP implicit price deflator and used in the manner described by equations 4 and 5 . In addition to deflation, there are other problems associated with this variable. Ideally, we would like it to measure the expenses incurred for activities which do not enter the production function directly and do not represent advertising or promotional activities. There are four possible sources of difficulties with this variable: (1) true expenditures may be distorted for publicity purposes; (2) the tax rule may influence the accounting procedures used; (3) the definition of research and development activity may not be the same for all the firms; (4) some research and development may be government financed.

1. I agreed not to identify the firms in the study in order to persuade them to supply the data. It is therefore difficult, considering the number that did not respond, to rationalize the first proposition. Given that the costs of reporting are almost zero, one might expect firms to reveal the data and to compete with each other in inflating the figures, if it were true that this type of advertising is profitable.

2. The effect of tax rules can be a real one. Clearly, if treatment of these expenditures for corporate tax purposes has changed over time, the behavior of this item over time will be affected. If this is the only source of error, the ranking of the firms does not necessarily change with respect to measures defined by equations 4 and 5 . However, we

${ }^{14}$ The deflation of retirements is a poor approximation. However, its effect is not significant, since (1) none of the firms retired more capital during 1934-46 than they held in 1933, and (2) retirements during 1947-57 amounted to 5 to 15 per cent of gross investments during this period. There were few mergers. Only one of them amounted to more than 3 per cent of the plant and equipment of the firm in the year of merger. In this case the plant and equipment of the new firm was measured as described in the text. In the rest of the cases, the price paid for the capital was deflated by that year's price indexes. 
would expect some "padding" of research and development expenditures if they were fully deductible, and the incidence of this padding might not be the same for all firms. As a matter of fact, since 1954 all research and development other than laboratory and equipment investments have been fully deductible.

3. It is frequently thought that the definition of research and development is not the same among firms. In three interviews, controllers, after consulting their data sheets, told me that the most liberal definition of research and development expenditures would inflate their figures from 10 to 20 per cent.

Let us take 20 per cent as the maximum error of measurement in research and development expenditures. The range over all eighteen chemical firms of the research and development measure $R_{i}$ defined by equation 4 is from 1 per cent to 11 per cent. However, for most firms it is between 2 and 8 per cent. Let us use 5 per cent to illustrate our point. This means that if the numerator of equation 4 is inflated by 10 per cent, the measure itself will be inflated to 5.5 per cent. If we take 20 per cent as the maximum inflation figure, we increase our measure by one percentage point. Table 1 shows the frequency distribution of firms with respect to the measure of 4 .

TABLE 1

Frequency Distribution of Firms, by Research and Development Expenditures Deflated by Average Total Weighted INPuts of Labor and Capital, Chemical Firms

\begin{tabular}{lcccccccccccc}
\hline \hline & \multicolumn{10}{c}{ Percentage Interval } \\
\cline { 2 - 10 } & $1-2$ & $2-3$ & $3-4$ & $4-5$ & $5-6$ & $6-7$ & $7-8$ & $8-9$ & $9-10$ & $10-11$ & Total \\
\hline Number of firms & 1 & 1 & 4 & 4 & 2 & 2 & 2 & 0 & 1 & 1 & 18 \\
\hline
\end{tabular}

A scatter diagram with the rate of growth in productivity on the vertical axis and the measure of research and development on the horizontal axis was investigated. The points lie around a positively sloped line. Even a 20 per cent error, which will affect the adjacent cells of the frequency table above, will not alter the positive character of the relationship. However, there is no way to tell whether the degree of correlation will increase or decrease.

4. Few firms that supplied research and development expenditures in their annual reports specified that government sponsored research and development were excluded. The firms that supplied this informa- 
tion upon request were asked to give only the concern's expenditures on research and development but it is not certain that they did so. It can be seen from National Science Foundation surveys ${ }^{15}$ that the government finances only about 8 per cent of the total research and development in the chemical industry. Furthermore, if we assume realistically that relatively large firms are the recipients of government contracts, we can be reasonably sure that although this source of discrepancy increases the variation in the measures of research and development it does not give rise to any spurious correlation since, as will be seen, the correlations between size and the research and development measures are not strong.

In conclusion, then, although errors of measurements may exist, it is unlikely that they have an appreciable influence on the results.

\section{The Empirical Results}

\section{TEST OF THE HYPOTHESIS}

HENCEFORTH, the rate of growth of productivity will be denoted by $\dot{P}$. As indicated earlier, the basic data from which the rate of growth in productivity is obtained for each firm is the time series measure of its productivity. For the chemical industry these time series are available from 1947 to 1957 for thirteen firms, from 1948 to 1957 for four firms, and from 1949 to 1957 for one firm. $\dot{P}$ was obtained by using output and, alternatively, value added in equation 9 with $P_{o}$ being the value of $P$ in the earliest year of the series, either 1947 or 1948 or 1949. Chart 1 shows the behavior of the measures of productivity of the eighteen chemical firms over the years 1947-57. Chart 2 summarizes the same information for five drug and pharmaceutical concerns for 1947-57.

The boxes at the bottom of Charts 1 and 2 supply us with information about the pattern of change in the productivity measures. The great majority of firms had an increase in productivity during 1947-50, 1952-53, and 1954-55, and a general decline during 1953-54. Approximately 50 per cent of the firms had increases and the rest, decreases in their productivity during the remainder of the period. These patterns of change do not coincide exactly with business cycle years.

These patterns of change raise grave problems in choosing a period for obtaining rates of growth of the productivity of the firms. As we

\footnotetext{
${ }^{15}$ Science and Engineering in American Industry, Final Report on a 1953-1954 Survey, National Science Foundation 56-16, 1956.
} 


\section{CHART 1}

Indexes of Productivity Measures, Using Output, Solid Lines, and Value Added, Broken Lines, Chemical Firms
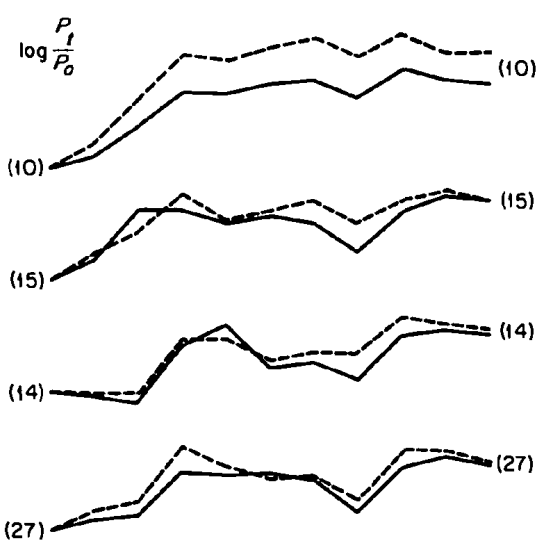

(8)

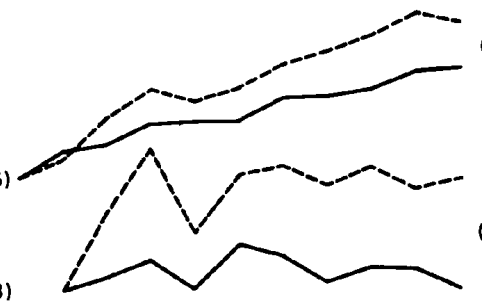

(9)

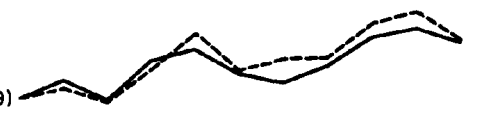

(25)

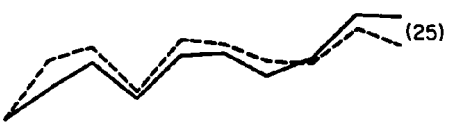

(13)

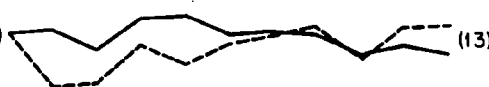

(22)
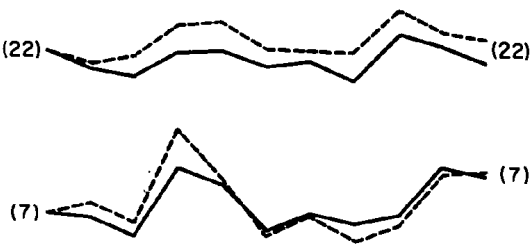

(23)

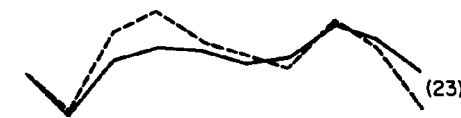

(4)

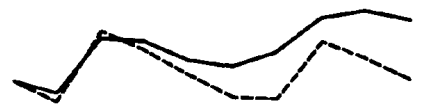

(4)

(20)

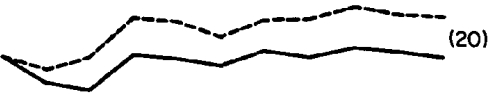

(2)

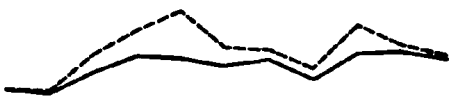

(28)

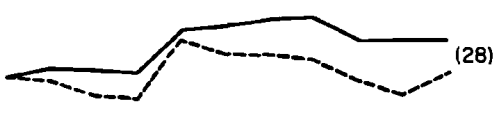

\begin{tabular}{|c|c|c|c|c|c|c|c|c|c|c|c|c|c|c|c|c|c|c|c|c|}
\hline 4 & 7 & 9 & 3 & 4 & 6 & 1 & 7 & 4 & 3 & \multirow{2}{*}{$\begin{array}{l}(--\infty) \\
\text { Increase } \\
(\square)\end{array}$} & 2 & 5 & 8 & 3 & 2 & 5 & 3 & 8 & 3 & 3 \\
\hline 4 & 4 & 9 & 4 & 4 & 6 & 1 & 8 & 6 & 0 & & 3 & 4 & 8 & 3 & 4 & 5 & 4 & 8 & 6 & 4 \\
\hline 3 & 2 & 0 & 6 & 5 & 3 & 8 & 2 & 5 & 6 & \multirow{2}{*}{$\begin{array}{l}(--) \\
\text { Decrease } \\
(\underline{ })\end{array}$} & 4 & 3 & 1 & 6 & 7 & 4 & 6 & 1 & 6 & 6 \\
\hline 3 & 5 & 0 & 5 & 5 & 3 & 8 & 1 & 3 & 9 & & 3 & 4 & 1 & 6 & 5 & 4 & 5 & 1 & 3 & 5 \\
\hline
\end{tabular}

\begin{tabular}{|c|c|c|c|c|c|c|c|c|c|c|}
\hline \multirow{2}{*}{$\begin{array}{c}(--\infty) \\
\text { Increase } \\
(\longrightarrow)\end{array}$} & 6 & 12 & 17 & 6 & 6 & 11 & 4 & 15 & 7 & 6 \\
\hline & 7 & 8 & 17 & 7 & 8 & 14 & 5 & 16 & 12 & 4 \\
\hline \multirow{2}{*}{$\begin{array}{c}(---) \\
\text { Decrease } \\
(\underline{-})\end{array}$} & 7 & 5 & 1 & 12 & 12 & 7 & 14 & 3 & 11 & 12 \\
\hline & 6 & 9 & 1 & 11 & 10 & 7 & 13 & 2 & 6 & 14 \\
\hline
\end{tabular}




\section{CHART, 2}

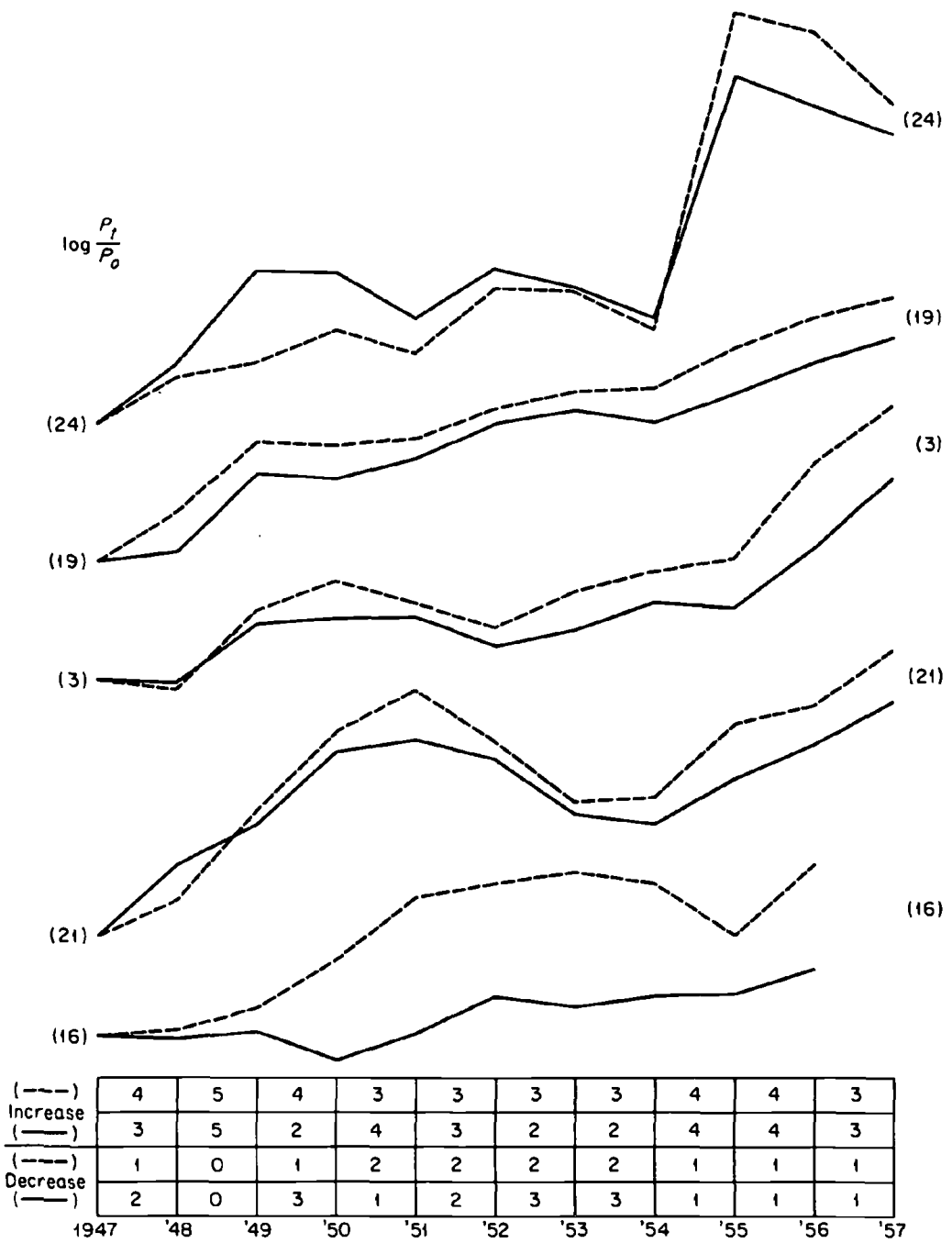

Indexes of Productivity Measures, Using Output, Solid Lines, and Value Added, Broken Lines, Drug and Pharmaceutical Firms

expect research and development to affect productivity only with a lag, we want to explain productivity changes by means of previous research and development. As data on such expenditures are not available before 1947 for most of the firms in the sample, we are forced 
to break up 1947-57 and use research and development in the early years to explain the productivity changes in later years. We would expect that some lags may give better results than no lag at all, depending on the behavior of research and development activity over time. Table 2 summarizes the regression results of the rates of growth of productivity (using value added) and the research and development measures for lags ranging from zero to five years.

\section{TABLE 2}

Simple $r^{2}$ 's of the Rate of Growth of Productivity $(\dot{P})$ and Average Research and Development Deflated by a Weighted Average of Total Inputs $\left(R_{i}\right)$, AND Average Research and Development Divided by Real Gross Plant and Equipment $\left(R_{k}\right)$, for LAGs Ranging from Zero to Five YeARs, ChemiCal Firms

\begin{tabular}{|c|c|c|c|c|c|c|c|}
\hline $\begin{array}{c}\text { Independent } \\
\text { Variables }\end{array}$ & $\begin{array}{c}P \\
(47-57)\end{array}$ & $\begin{array}{c}\dot{P}_{1} \\
(48-57)\end{array}$ & $\begin{array}{c}\text { Depen } \\
P_{2} \\
(47,48,52, \\
55,56,57)\end{array}$ & $\begin{array}{c}\text { dent Varic } \\
\dot{P}_{3} \\
(49-57)\end{array}$ & $\underset{(50-57)}{P_{4}}$ & $\begin{array}{c}P_{5} \\
(51-57)\end{array}$ & $\begin{array}{c}P_{\mathrm{B}} \\
(52-57)\end{array}$ \\
\hline $\begin{array}{l}R_{i}(47-56) \\
R_{k}(47-56) \\
R_{i}(47-55) \\
R_{k}(47-55) \\
R_{i}(47-54) \\
R_{k}(47-54) \\
R_{k}(48-55) \\
R_{k}(49-56) \\
R_{k}(50-57) \\
R_{i}(47-53) \\
R_{k}(47-53) \\
R_{k}(48-54) \\
R_{k}(49-55) \\
R_{k}(50-56) \\
R_{k}(51-57) \\
R_{i}(47-52) \\
R_{k}(47-52) \\
R_{k}(48-53) \\
R_{k}(49-54) \\
R_{k}(50-55) \\
R_{k}(51-56) \\
R_{k}(52-57)\end{array}$ & $\begin{array}{l}0.668 \\
0.734\end{array}$ & $\begin{array}{l}0.593 \\
0.701\end{array}$ & $\begin{array}{l}0.619 \\
0.604\end{array}$ & $\begin{array}{l}0.533 \\
0.654\end{array}$ & $\begin{array}{l}0.389 \\
0.521 \\
0.508 \\
0.508 \\
0.510\end{array}$ & $\begin{array}{l}0.452 \\
0.442 \\
0.429 \\
0.429 \\
0.424 \\
0.413\end{array}$ & $\begin{array}{l}0.270 \\
0.163 \\
0.174 \\
0.180 \\
0.182 \\
0.181 \\
0.181\end{array}$ \\
\hline
\end{tabular}

$P=$ Rate of growth in productivity (using value added), equation (9).

$R_{i}=\frac{\sum(\text { R.D. })_{t}}{\sum\left(L^{a} K^{1-a}\right)_{t}}=\begin{aligned} & \text { Average research and development expenditures deflated by a } \\ & \text { weighted average of total inputs. The years relevant to each } R_{i} \\ & \text { are indicated in the brackets. }\end{aligned}$ $R_{k}=\frac{\sum(\text { R.D. })_{t}}{\sum(K)_{t}}=\begin{aligned} & \text { Average research and development expenditures deflated by } \\ & \text { average gross plant and equipment. The years relevant to each }\end{aligned}$ $R_{k}$ are indicated in the brackets. 
TABLE 3

SIMPLE $r^{2}$ 's OF $R_{k}$ MEASURE OF RESEARCH AND DEVELOPMENT IN 1949, 1952, AND 1955, Chemical Firms

\begin{tabular}{ccc}
\hline \hline & $R_{k}(1952)$ & $R_{k}(1955)$ \\
\hline$R_{k}(1949)$ & 0.973 & 0.951 \\
$R_{k}(1952)$ & & 0.968 \\
\hline
\end{tabular}

See Table 2 above for the definition of $R_{k}$.

First note that the $r^{2}$ 's of the three rate of growth of productivity variables, $\dot{P}_{4}, \dot{P}_{5}$, and $\dot{P}_{6}$, with measures of research and development expenditures are highest when research and development is lagged by three, four and two years, respectively.

Second, note that the $r^{2}$ 's of the rate of growth of productivity variables $\dot{P}, \dot{P}_{1}, \dot{P}_{2}$, and $\dot{P}_{3}$, with research and development measures decline almost monotonically as we shorten the period upon which the change in productivity is based. The shorter periods begin with Korean war years of 1950-52, include the recession of 1953-54, and end with the five months recession of 1957 . There is no reason to expect that all firms will be affected to the same extent in these years. In fact we have seen that even the directions of the change in productivity among the firms were different during the years 1950-52 and 1955-57. Therefore, we would expect the influence of research and development on productivity to be overshadowed by the effects of these "abnormal" years and the idiosyncrasies of price changes, to be discussed later. These effects or errors will assume increasingly heavier weights as we shorten the period; affecting the slope of the regression line-the rate of growth of productivity-more and more.

A logical question now is, if we know that certain years contain errors, why use longer periods in order to minimize the effect of the errors when we can eliminate them entirely by excluding these particular years? This alternative was not chosen for two reasons. One reason was the lack of a satisfactory rule for discarding years. One might first disregard the recession years, then perhaps the Korean war years, leaving presumably full employment years. That is, we might disregard the years 1949, 1950, 1951, 1953, 1954, and possibly also 1957. The regression results obtained when the rate of growth of productivity was calculated using data on 1947-48, 1952, and 1955-57 are presented in Table 2. The $r^{2}$ of the rates of growth of productivity for these years $\left(\dot{P}_{2}\right)$ with $R_{i}$ is 0.62 and that with $R_{k}$ is 0.60 . This 
compares well with 0.67 and 0.73 when all the observations in the period are used. ${ }^{16}$

The second reason for not excluding the years containing errors was, how justifiable is it to eliminate recessions and war years and leave "normal" years untouched? Although one may very well call these years normal for the economy-they were characterized by full employment, etc.-it is questionable that these years would be "normal" for all firms in the chemical industry. It should be noted that we found above that changes in the productivity measures did not correspond exactly with business cycle years. Furthermore, firms had different experiences even in "normal" years. Rather than remove the recession years, it might be more meaningful to look at a complete cycle(s). If the business cycle affects the relationships we are investigating, looking at only parts of a cycle will bias our results; for purposes of generality, we would favor a complete cycle. These considerations persuaded us to choose the method that utilized all the observations in calculating our rate of growth of productivity.

The regression results of the rates of growth using value added in equation 9 and two alternative measures of research and development expenditures defined by equations 4 and 5 are summarized in Table 4. Both regression coefficients are significant at the 1 per cent two-tail level. The regressions indicate that the greater the ratio of research and development expenditures to total inputs or to gross real plant and equipment the greater the rate of growth of productivity.

${ }^{16}$ After the surrender of Germany in 1945, confiscated German patents were made available (at no cost) to U.S. firms. It has been speculated that the effects of these patents may be present in my measure of productivity, as the patents may have been assimilated as late as 1947 or 1948 . It seems unlikely that these effects will alter my results for two reasons. In the first place, it is not obvious that the acceptance of these free patents by firms in the same industry should be correlated with the independent variables, hence it should not negate the results. On the other hand, to the extent that the acceptance does affect productivity but is uncorrelated with the independent variables, the unexplained variance of the dependent variable is increased. Secondly, the lag between the availability of these patents and the impact on productivity would arise only from investment in plant and equipment, as there is no lag analogous to that of research and development where it takes time to develop technology. Thus this German patent effect was perhaps worked off by 1947.

Further, for five firms for which research and development data is available before 1947, the behavior of $R_{k}$ before 1947 was similar to its behavior since that date. Also note Table 3, where we see very high correlations between $\boldsymbol{R}_{k}$ (for all eighteen firms) for the years 1949,1952 , and 1955 . This evidence leads one to believe the research and development activity for 1945 and 1946 did not differ greatly from that of years for which we have data. Thus, even if there is a substantial lag between research and development and $\dot{P}$, our results should not be altered by previous research and development, since we believe our 1947-57 measure of $R$ and $D$ to summarize the immediately preceding period as well. 
TABLE 4

Simple Regression Coefficients and Their Standard Errors, and the Coefficients of Determination of the Rate of Growth of Productivity $(\not{P})$ and Two Alternative Measures of Research and Development $\left(\boldsymbol{R}_{i}\right.$ AND $\left.\boldsymbol{R}_{k}\right)$, CHEMICAL FIRMS

\begin{tabular}{ccc}
\hline \hline $\begin{array}{c}\text { Independent } \\
\text { Variable }\end{array}$ & $\begin{array}{c}\text { Dependent Variable } \boldsymbol{P} \\
\text { Regression Coefficients } \\
\text { and Standard Errors }\end{array}$ & $\mathbf{r}^{\mathbf{2}}$ \\
\hline$R_{i}$ & 0.250 & 0.67 \\
$R_{k}$ & $(0.044)$ & 0.73 \\
& 0.294 & \\
\hline
\end{tabular}

See Table 2 above for definitions of $\dot{P}, R_{i}$, and $R_{k}$.

Figures in parentheses are standard errors.

With the exception of average gross plant and equipment $(K)$, which is $\$ 1,000$, the variables are measured in percentages.

In order to investigate the sensitivity of the results to a different formulation of the share of labor (footnote 8 ) and a different concept of capital (footnote 12), $\dot{P}$ was adjusted for these effects and the results obtained are summarized in Table $5 .{ }^{17}$ It can be seen that the results

TABLE 5

Simple Regression Coefficients, Coefficients of Determination of Rates of Growth of Productivity $\left(\dot{P}^{*}, \dot{P}^{* *}, \dot{P}^{* * *}\right)$, and a Measure of Research and Development $\left(R_{k}\right)$, Chemical Firms

\begin{tabular}{ccc}
\hline \hline Dependent Variable & $\begin{array}{c}\text { Independent Variable } \boldsymbol{R}_{k} \\
\text { Regression Coefficients }\end{array}$ & $\boldsymbol{r}^{2}$ \\
\hline$P^{* *}$ & 0.294 & 0.733 \\
$P^{* *}$ & 0.293 & 0.732 \\
$P^{* * *}$ & 0.293 & 0.731 \\
\hline
\end{tabular}

$P^{*}=$ The rate of growth in productivity using the share of labor obtained by an alternative formulation.

$P^{* *}=$ The rate of growth in productivity when total gross capital is used instead of gross plant and equipment.

$\dot{P}^{* * *}=$ The rate of growth in productivity when total gross capital and the share of labor determined by alternative formulation are used.

of this study do not depend upon the particular concept of capital employed or the formulation of the share of labor. Furthermore, to test for the effects of royalties paid (footnote 7), residuals of the regression line of $\dot{P}$ on $R_{k}$ were plotted against the average ratio of royalties

${ }^{17}$ For details of this adjustment see Jora R. Minasian, "The Economics of Research and Development," unpublished Ph.D. dissertation, University of Chicago, 1960, pp. 33-34. 
paid to research and development expenditures. A positive relation was expected but the result was equivocal. ${ }^{18}$

Three broad questions can be asked at this point: (1) Are there any omitted variables which may cause the rate of growth in productivity to be positively correlated with research and development expenditures? That is, are rates of growth in productivity and research and development positively correlated only because each one of them is so related with some other causal variable(s) not introduced in the regression equation? (2) Are there other variables which belong in the regression equation because they can explain some of the changes in the productivity measure that are unexplained by research and development? (3) Is there a variable that causes research and development, and affects $\dot{P}$ only via research and development?

In the pages that follow, the method is to insert additional variables in the regressions of productivity change on research and development expenditures. These variables will include profitability, gross investment, and a few scale measures. We shall see if these additional variables increase the explanation of the dependent variable, and if they, any or all of them, reduce the significance of the research and development variable.

\section{ALTERNATIVE HYPOTHESIS, PROFITABILITY}

The first general alternative hypothesis states that profitability is the important variable which determines research and development expenditures and is associated with the rate of growth in productivity, and that the observed correlation between rate of growth of productivity and research and development activity is spurious. In this study the term profitability will be defined as profits deflated by a size variable, gross plant and equipment.

The general hypothesis is that profits play the role of a budget restraint. The implications are: (1) initial profitability should be better correlated with final research and development than vice versa; (2) research and development may or may not affect productivity, but being a "superior consumption good" will be "consumed" by highly profitable firms; and (3) if profitability determines research and development, which in turn affects $\dot{P}$, which finally controls vrofitability, then profitability at the end of the period should be significantly correlated with initial profitability.

Let us investigate the simple coefficients of determination of the 18 Ibid., Graph 15, App. I. 
relevant variables. Table 6 gives these coefficients for profitability and research and development variables.

TABLE 6

Simple $r^{2}$ 's of the Rate of Growth of Productivity $(\dot{P})$, Average Research and Development Deflated by a Weighted Average of Total Inputs $\left(R_{i H}\right)$ and $\left(R_{i E}\right)$, Average Research and Development Deflated by Real Gross Plant and EQUipment $\left(R_{k B}\right)$ aNd $\left(R_{k E}\right)$, AND Profitability in 1947-50 $\left(I_{k}\right)$, IN 1955-56 $\left(I_{E}\right)$, CHEMICAL FiRMS

\begin{tabular}{lcccccc}
\hline \hline & $R_{i B}$ & $R_{k B}$ & $R_{i E}$ & $R_{k E}$ & $I_{B}$ & $I_{E}$ \\
\hline$\not P$ & 0.60 & 0.72 & 0.71 & 0.73 & 0.01 & 0.52 \\
$R_{i B}$ & - & - & 0.72 & - & 0.01 & 0.34 \\
$R_{k B}$ & - & - & - & 0.93 & 0.09 & 0.72 \\
$R_{i E}$ & - & - & - & - & 0.01 & 0.36 \\
$R_{k E}$ & - & - & - & - & 0.10 & 0.74 \\
$\boldsymbol{I}_{B}$ & - & - & - & - & - & 0.21 \\
\hline
\end{tabular}

$P=$ See Table 2 above.

$R_{i B}$ and $R_{k B}=$ Same as $R_{t}$ and $R_{k}$ in Table 2 but for 1947-50 instead.

$R_{i E}$ and $R_{k E}=$ Same as $R_{i}$ and $R_{k}$ in Table 2 but for 1955-56 instead.

Net income after taxes +interest payments

$I_{B}=\frac{\text { deflated by GNP implicit price deflator }}{\text { Real gross plant and equipment }} \times \frac{1}{4}=$ profitability in 1947-50.

$I_{E}=$ Same as $I_{B}$ above but for 1955-56 instead.

First, note that the $r^{2}$ 's of the two research and development measures at the beginning of the period $R_{k B}$ and $R_{i B}$ with profitability at the end of the period $I_{E}$ are, respectively, 0.34 and 0.72 , while the $r^{2}$ s of profitability at the beginning of the period $I_{B}$ with the two measures of research and development at the end of the period $R_{i E}$ and $R_{k E}$ are, respectively, 0.01 and 0.10 . These results indicate that the research and development at the beginning of the period explains profitability at the end of the period much better than profitability at the beginning of the period explains the research and development expenditures at the end of the period. This is exactly the opposite of implication 1 of the alternative hypothesis of profitability.

Second, note that the $r^{2}$ of the rate of growth in productivity $\dot{P}$ with average research and development expenditures deflated by total weighted inputs, $1955-56, R_{i E}$ is 0.71 , and that of $\dot{P}$ with average research and development expenditures divided by total gross plant and equipment, 1955-56, $R_{k E}$ is 0.73 , while the $r^{2}$ of the rate of growth in productivity with profitability in $1947-50 I_{B}$ is only 0.01 . Also note that the $r^{2}$ 's of the rate of growth in productivity with the two research and development measures for $1947-50, R_{i B}$ and $R_{k B}$, are 0.60 and 
0.72 , respectively, while the $r^{2}$ of the rate of growth of productivity with the profitability measure in $1955-56, I_{E}$, is only 0.52 . The above results indicate that the research and development of both the beginning and the end of the period explain the rates of growth in productivity better than the profitability at the end of the period and much better than the profitability at the beginning of the period, which is inconsistent with implication 2.

Finally, note that the $r^{2}$ between initial and final profitability, $I_{B}$ and $I_{E}$, respectively, is only 0.21 , which is not significant at 5 per cent (one tail). Thus, implication 3 of the alternative hypothesis also fails to be borne out. To the contrary we see that the correlations $\left(r^{2} s\right)$ between initial research and development and initial profitability are only 0.01 and 0.09 ; while between final research and development and final profitability the $r^{2}$ 's are 0.36 and 0.74 . It seems research and development affects profitability, rather than the other way around; our simple correlations tell us to reject the alternative hypothesis in favor of the one advanced in this study.

To obtain a more conclusive test of this alternative hypothesis, profitability and research and development measures are introduced as two different independent variables in regression equations with the rate of growth in productivity as the dependent variable. If research and development is the effect of profitability, we should expect lagged profits to steal away the explanatory power of research and development when both are present in a multiple regression. ${ }^{19}$ The results of eight such regressions are summarized in Table 7.

In regressions 1 and 2 the partial regression coefficients of $I_{B}$ are not significant even at the 20 per cent two-tail level, and one in 2 has the wrong sign. However, both the $R_{i E}$ and $R_{k E}$ variables have partial regression coefficients significant at the 1 per cent two-tail level, explaining 70 per cent and 76 per cent, respectively, of the variation in the rate of growth in productivity, while lagged profitability explains less than 0.1 per cent and 10 per cent, respectively, of the variation.

Regressions 3 and 4 use lagged research and development measures, $R_{i B}$ and $R_{k \dot{B}}$, and profitability at the end of the period, $I_{E}$. Again, partial regression coefficients of $R_{i B}$ and $R_{k B}$ are significant at the 1 per cent two-tail level. The partial regression coefficient of $I_{E}$ is significant at the 1 per cent two-tail level in regression 3 ; it is not significant at even the 20 per cent two-tail level in regression 4 and in addition it has

${ }^{19}$ Or perhaps we might find a high multiple coefficient of determination but insignificant coefficients for both variables because of high multicollinearity. 
the wrong sign. In terms of partial coefficients of determination, $R_{i B}$ and $R_{k B}$ both explain approximately 40 per cent of the variation in the rate of growth of productivity, while profitability at the end of the period explains, at best, 27 per cent of the variation. ${ }^{20}$

TABLE 7

Multiple Regressions of the Rate of Growth of Productivity on Research and Development and Profitability Variables Contained in Table 6, CHEMICAL FIRMS

\begin{tabular}{|c|c|c|c|c|c|c|c|}
\hline \multirow{2}{*}{$\begin{array}{c}\text { Regression } \\
\text { Number and } \\
\text { Dependent } \\
\text { Variable }\end{array}$} & \multicolumn{6}{|c|}{ Independent Variable } & \multirow[b]{2}{*}{$R^{2}$} \\
\hline & $R_{i B}$ & $R_{k B}$ & $R_{i E}$ & $R_{k E}$ & $I_{B}$ & $I_{E}$ & \\
\hline (1) $P$ & & & $\begin{array}{c}0.181 \\
(0.030) \\
0.703\end{array}$ & & $\begin{array}{c}0.002 \\
(0.018) \\
0.001\end{array}$ & & 0.707 \\
\hline (2) $P$ & & & & $\begin{array}{c}0.291 \\
(0.042) \\
0.759\end{array}$ & $\begin{array}{c}(-) 0.023 \\
(0.017) \\
0.106\end{array}$ & & 0.762 \\
\hline (3) $P$ & $\begin{array}{c}0.213 \\
(0.066) \\
0.399\end{array}$ & & & & & $\begin{array}{c}0.034 \\
(0.014) \\
0.274\end{array}$ & 0.712 \\
\hline (4) $P$ & & $\begin{array}{c}0.449 \\
(0.138) \\
0.413\end{array}$ & & & & $\begin{array}{c}(-) 0.000 \\
(0.022) \\
0.000\end{array}$ & 0.719 \\
\hline (5) $P$ & $\begin{array}{c}0.306 \\
(0.065) \\
0.598\end{array}$ & & & & $\begin{array}{c}0.002 \\
(0.021) \\
0.001\end{array}$ & & 0.603 \\
\hline (6) $P$ & & $\begin{array}{c}0.476 \\
(0.073) \\
0.740\end{array}$ & & & $\begin{array}{c}(-) 0.021 \\
(0.018) \\
0.088\end{array}$ & & 0.743 \\
\hline (7) $P$ & & & $\begin{array}{c}0.138 \\
(0.033) \\
0.543\end{array}$ & & & $\begin{array}{c}0.028 \\
(0.012) \\
0.253\end{array}$ & 0.781 \\
\hline (8) $P$ & & & & $\begin{array}{c}0.290 \\
(0.083) \\
0.447\end{array}$ & & $\begin{array}{c}(-) 0.005 \\
(0.022) \\
0.003\end{array}$ & 0.735 \\
\hline
\end{tabular}

See Table 6 for definitions of the variables.

In each regression, the partial regression coefficient is given in the first row, its standard error (in parentheses) in the second row, and the partial coefficient of determination in the third row. None of the multiple coefficients of determination are corrected for degrees of freedom. The results of further multiple regressions will be presented in the same manner.

${ }^{80}$ Relationships, theoretical and empirical, between research and development and profitability are investigated later on in this section. 
Finally, it is interesting to test the following two propositions: first, that the effect of research and development on $\dot{P}$ takes place with a lag, and, second, that the lag between profits and research and development may be shorter than the period used in the above regressions, i.e., 1947-50 to 1955-56. Regressions 5 and 6 use both lagged research and development and lagged profitability. Here again both measures of research and development expenditures have partial regression coefficients significant at the 1 per cent two-tail level. The profitability variable has partial regression coefficients insignificant even at the 10 per cent two-tail level. Regressions 7 and 8 use end-of-period values for both variables and the results are similar to those of 5 and 6 , except that profitability is significant when measured at the end of the period. This is consistent with a belief that productivity affects profitability.

It is, therefore, concluded that the alternative hypothesis of profitability is false. Furthermore, the above results indicate that it is more probable that profitability is the result of past research and development activity, than the other way around.

\section{ALTERNATIVE HYPOTHESIS, INVESTMENT IN PLANT AND EQUIPMENT}

It might be expected that the rate of growth of productivity $\dot{P}$ would be explained by investment in plant and equipment because a firm without research and development may have gained in $\dot{P}$ through expansion, and new capital incorporates new technologies provided by the producers of the capital which may not have been corrected for in our measure of capital. ${ }^{21}$ Therefore, we might expect a positive correlation between $\dot{P}$ and investment in plant and equipment.

21 "Opportunity" is another alternative hypothesis which states that research and development expenditures are determined by still another factor, that is the technical possibilities which may vary among firms. Therefore, the firm will indulge in such activity only if its production processes readily lend themselves to improvement. This seems illogical. If returns are high to research and development for particular product mixes, a firm should (and would) carry on such activity whether it produces such mixes or not, as it can either alter its mix to take advantage of the resulting improvement, or sell that improvement to a firm that can use it directly.

Strictly speaking, we have three cases: (1) assume that there is no mobility in the industry-ill-fated firms can not change their product mix-thus the ranking of the firms with respect to research and development does not change over time, (2) there is mobility, thus the ranking of firms does change over time, and (3) research and development creates opportunities and the intensity thereof is governed by subjective probabilities and the risk preference functions of the decision makers.

We saw in Table 3 that the ranking of the firms did not change during the period which is consistent with propositions 1 and 3 . I believe, however, that profit motives are strong and there is mobility in the market, which leaves me to conclude in favor of case 3 above. 
The reasons that led us to deflate research and development by a size variable now lead us to deflate investment in plant and equipment by a size variable. The simple coefficients of determination are given in Table 8.

\section{TABLE 8}

Simple $r^{2}$ 's of the Rate of Growth of Productivity $(\dot{P})$, Average Research and DeVelopment Deflated by a Weighted AVerage of Total INPUTS $\left(R_{i B}\right)$ and $\left(R_{i E}\right)$, Average Research and Development Deflated by Real Gross Plant and EQUipment $\left(R_{k B}\right)$ AND $\left(R_{k E}\right)$, AND AVerage Gross INVEstment Deflated by A Weighted AVerage of Total Inputs $\left(G_{B}\right)$ AND $\left(G_{E}\right)$,

CHEMICAL Firms

\begin{tabular}{lcccccc}
\hline \hline & $\overline{R_{i B}}$ & $\boldsymbol{R}_{k B}$ & $\boldsymbol{R}_{i E}$ & $\boldsymbol{R}_{k E}$ & $G_{B}$ & \multicolumn{1}{c}{$G_{E}$} \\
\hline$P$ & 0.60 & 0.72 & 0.71 & 0.73 & $(-) 0.02$ & 0.00 \\
$R_{i B}$ & - & - & 0.72 & - & $(-) 0.00$ & $(-) 0.01$ \\
$R_{k B}$ & - & - & - & 0.93 & $(-) 0.02$ & $(-) 0.09$ \\
$R_{i E}$ & - & - & - & - & $(-) 0.03$ & $(-) 0.01$ \\
$R_{k E}$ & - & - & - & - & $(-) 0.05$ & $(-) 0.11$ \\
$G_{B}$ & - & - & - & - & - & 0.00 \\
\hline
\end{tabular}

See Table 6 above for definitions of $(P),\left(R_{i B}\right),\left(R_{i E}\right),\left(R_{k B}\right)$, and $\left(R_{k E}\right)$.

$$
\begin{aligned}
& G_{B}=\frac{\sum_{t=47}^{50}(\mathrm{G} . \mathrm{I} .)_{t}}{\sum_{t=47}^{50}\left(L^{a} K^{1-a}\right)_{t}}=\begin{array}{l}
\text { Average gross investment in plant and equipment deflated } \\
\text { by a weighted average of total inputs, 1947-50. }
\end{array} \\
& G_{E}=\frac{\sum_{t=55}^{56}(\mathrm{G} . \mathrm{I})_{t}}{\sum_{t=55}^{56}\left(L^{a} K^{1-a}\right)_{t}}=\begin{array}{l}
\text { Average gross investment in plant and equipment deflated } \\
\text { by a weighted average of total inputs 1955-56. }
\end{array}
\end{aligned}
$$

The $r^{2}$ 's of the rate of growth in productivity $\dot{P}$ with two measures of research and development $R_{i E}$ and $R_{k E}$ are 0.71 and 0.73 , respectively, while the $r^{2}$ of $\dot{P}$ and average investment deflated by total weighted inputs in 1947-50, $G_{B}$, is 0.02. Furthermore, the $r^{2}$ 's of the rate of growth in productivity $\dot{P}$ with $R_{i B}$ and $R_{k B}$ are, respectively, 0.60 and 0.72 , while the $r^{2}$ of $\dot{P}$ with $G_{E}$ is 0.00 . It should be emphasized that none of the $r^{2}$ s of $\dot{P}$ with investment measures, both at the beginning and at the end of the period, are significant at even the 20 per cent twotail level.

In addition, the $r^{2}$ 's of the investment measure at the beginning of the period $G_{B}$ with $R_{i E}$ and $R_{k E}$ are, respectively, (-)0.03 and (-)0.05, while the $r^{2}$ 's of $R_{i B}$ and $R_{k B}$ with $G_{E}$ are, respectively, (-)0.01 and (-)0.09. Furthermore, the $r^{2}$ 's of $G_{E}$ and $G_{B}$ with $R_{i E}, R_{k E}$ and $R_{i B}$, 
$R_{k B}$, respectively, are (-)0.01, (-)0.11, (-)0.00 and (-)0.02. These results suggest that the decision to invest in plant and equipment and the decision to invest in research and development may be competitive in nature since they are negatively correlated. Again it should be emphasized that none of the $r^{2}$ 's relevant to the investment hypothesis are significant even at the 20 per cent two-tail level.

Multiple regression analysis, used in testing the profitability hypothesis, is also used for testing the investment hypothesis. The results of eight such regressions are summarized in Table 9.

TABLE 9

Multiple Regressions of the Rate of Growth of Productivity on Research and DeVELOPMENT and INVESTMENT Variables Contained in Table 8, Chemical Firms

\begin{tabular}{|c|c|c|c|c|c|c|c|}
\hline \multirow{2}{*}{$\begin{array}{c}\text { Regression } \\
\text { Number and } \\
\text { Dependent } \\
\text { Variable }\end{array}$} & \multicolumn{6}{|c|}{ Independent Variable } & \multirow[b]{2}{*}{$R^{2}$} \\
\hline & $R_{i B}$ & $R_{k B}$ & $R_{i E}$ & $\boldsymbol{R}_{k E}$ & $G_{B}$ & $G_{E}$ & \\
\hline (1) $P$ & & & $\begin{array}{c}0.183 \\
(0.031) \\
0.702\end{array}$ & & $\begin{array}{c}0.001 \\
(0.001) \\
0.002\end{array}$ & & 0.707 \\
\hline (2) $\dot{P}$ & & & & $\begin{array}{c}0.278 \\
(0.043) \\
0.732\end{array}$ & $\begin{array}{c}0.003 \\
(0.008) \\
0.012\end{array}$ & & 0.737 \\
\hline (3) $\dot{P}$ & $\begin{array}{c}0.311 \\
(0.064) \\
0.613\end{array}$ & & & & & $\begin{array}{c}0.008 \\
(0.012) \\
0.026\end{array}$ & 0.613 \\
\hline (4) $\dot{P}$ & & $\begin{array}{c}0.499 \\
(0.063) \\
0.805\end{array}$ & & & & $\begin{array}{c}0.024 \\
(0.009) \\
0.309\end{array}$ & 0.805 \\
\hline (5) $\dot{P}$ & $\begin{array}{c}0.304 \\
(0.063) \\
0.608\end{array}$ & & & & $\begin{array}{c}(-) 0.007 \\
(0.009) \\
0.041\end{array}$ & & 0.615 \\
\hline (6) $\dot{P}$ & & $\begin{array}{c}0.448 \\
(0.073) \\
0.714\end{array}$ & & & $\begin{array}{c}(-) 0.001 \\
(0.008) \\
0.001\end{array}$ & & 0.719 \\
\hline (7) $\dot{P}$ & & & $\begin{array}{c}0.184 \\
(0.030) \\
0.720\end{array}$ & & & $\begin{array}{c}0.009 \\
(0.011) \\
0.045\end{array}$ & 0.720 \\
\hline (8) $\dot{P}$ & & & & $\begin{array}{c}0.311 \\
(0.035) \\
0.841\end{array}$ & & $\begin{array}{c}0.027 \\
(0.008) \\
0.401\end{array}$ & 0.841 \\
\hline
\end{tabular}

See Table 8 for definitions of the variables.

See Table 7 for a description of the manner in which results are presented. 
In regression equations 1 and 2 the partial regression coefficients of $G_{B}$ are not significant even at the 20 per cent two-tail level. However, the partial regression coefficients of both $R_{i E}$ and $R_{k E}$ are significant at the 1 per cent two-tail level. Furthermore, the partial regression coefficient of $G_{E}$ is insignificant even at the 20 per cent two-tail level in regression 3 while it is significant at the 1 per cent two-tail level in regression 4. Both $R_{i B}$ and $R_{k B}$ have partial regression coefficients significant at the 1 per cent two-tail level. Regressions 5 and 6 use investment and both the research and development measures at the beginning of the period. Both partial regression coefficients of $G_{B}$ have the wrong sign and are not significant at even the 20 per cent twotail level, while both $R_{i B}$ and $R_{k B}$ are significant at the 1 per cent twotail level.

Finally, in regressions 7 and 8, which use end-of-period data, investment is highly significant in 8 but not in 7 , while research and development measures are significant in both.

The complete failure of investment to be related to either research and development or $\dot{P}$, and the complete lack of correlation of beginning period investment with $\dot{P}$ in the multiple regressions, are viewed as sufficient evidence to dismiss the investment hypothesis that a firm without research and development may have gained in $\dot{P}$ through expansion. However, the significant results in regressions 4 and 5 where end of period investment and $R_{k B}$ and $R_{k E}$, respectively, were used are consistent with the hypothesis that $\dot{P}$ affects investment (research results are commercialized) which may also be coupled with underestimation of capital in the sense that improvements in capital have not been corrected for. ${ }^{22}$

\section{ALTERNATIVE HYPOTHESIS, ECONOMIES OF SCALE}

\section{Economies of Scale to Production}

Our measure of the rate of growth, utilizing the assumption of constant return to scale, might show too large a productivity increase if there were economies of scale to production.

Our dependent variable is the rate of growth in productivity over

\footnotetext{
${ }^{22} \mathrm{~A}$ change in productivity caused by research and development will have two effects on the stock of capital as measured. The substitution effect will indicate a low gross stock while the scale effect will dictate a large stock. A priori, we cannot say which effect is stronger so we cannot predict the effect of research and development on future investment in the firm.
} 
the period. If there are economies of scale then we may expect some measure of the increase in scale to steal away the research and development variable's ability to explain $\dot{P}$. To test this hypothesis the percentage change in real output was correlated with the rate of growth in productivity. The simple $r^{2}$ of the rate of growth of productivity $\dot{P}$ with the percentage change in real output $(1947-56)$ is 0.023 , which is not significant even at the 10 per cent two-tail level. Because of this and similar insignificant results obtained in multiple regressions for an alternative measure, presented below, we did not compute the multiple regressions of $\dot{P}$ on research and development and the percentage change in output.

\section{Economies of Scale to Research and Development}

It is said that large firms are in a position to conduct research activity more effectively, presumably, because of economies of scale, diversification, and financial strength, as well as the uncertainty of the results and the waiting time involved.

Three scatter diagrams, the rate of growth of productivity $\dot{P}$ on average value added, $\dot{P}$ on average total weighted inputs, and $\dot{P}$ on average gross plant and equipment, were investigated. The three scatter diagrams were almost identical, indicating that all the measures reflect size equally well. Furthermore, the relationship could not be improved by a simple nonlinear function. To test this hypothesis, we chose average gross plant and equipment.

We have also investigated the percentage net increase in gross plant and equipment during this period in order to see whether the rate of change in size has any explanatory power. In this form it also incorporates something from the investment hypothesis and is another, perhaps inferior, variable reflecting the economies of scale to production.

The $r^{2}$ s are given in Table 10. The $r^{2}$ of the rate of growth in productivity $\dot{P}$ with average gross plant and equipment $K$ is 0.01 and that of $\dot{P}$ with percentage net additions to gross plant and equipment $\dot{K}$ is $(-) 0.07$. Furthermore, the $r^{2}$ of research and development deflated by total weighted inputs $1947-56, R_{i}$ with $K$ is 0.03 and that of $R_{i}$ with $\dot{K}$ is $(-) 0.04$. These $r^{2}$ s are $(-) 0.00$ and $(-) 0.15$, respectively, when research and development expenditure divided by gross plant and equipment $R_{k}$ is used. None of the $r^{2}$ 's are significant at the 5 per cent two-tail level. 
TABLE 10

Simple $r^{2}$ s of the Rate of Growth of Productivity $(\dot{P})$, Average Research and Development Deflated by a Weighted Average of Total Inputs, 1947-56 $\left(R_{i}\right)$, Average Research and Development Deflated by Real Gross Plant and Equipment, 1947-56, $\left(R_{k}\right)$, Average Gross Plant and Equipment, 1947-56 $(K)$, and Percentage Net Additions to Gross Plant and Equipment, 1947-56

$(\dot{K})$, Chemical Firms

\begin{tabular}{ccccc}
\hline & $R_{i}$ & $R_{k}$ & \multicolumn{1}{c}{$K$} & \multicolumn{1}{c}{$\dot{K}$} \\
\hline$\dot{P}$ & 0.67 & 0.73 & 0.01 & $(-) 0.07$ \\
$R_{i}$ & & 0.74 & 0.03 & $(-) 0.04$ \\
$R_{k}$ & & & $(-) 0.00$ & $(-) 0.15$ \\
$K$ & & & & 0.02
\end{tabular}

See Table 2 above for definitions of variables $(P),\left(R_{i}\right)$, and $\left(R_{k}\right)$.

$$
\begin{aligned}
& K=\frac{\sum_{t=47}^{56} K_{t}}{10}=\text { Average gross plant and equipment in 1947-56. } \\
& \dot{K}=\frac{\sum_{t=47}^{56}(\text { G.I. }- \text { R. })_{t}}{\sum_{t=47}^{48} K_{t}}=\begin{array}{c}
\text { Average percentage net additions to gross plant and equip- } \\
\text { ment in 1947-56. } R=\text { Retirement. }
\end{array}
\end{aligned}
$$

The results of the multiple regressions appear in Table 11. Neither of the partial regression coefficients of average gross plant and equipment in regression equations 1 and 2 is significant at even the 20 per cent two-tail level. On the other hand, both measures of research and development $R_{i}$ and $R_{k}$ have partial regression coefficients significant at the 1 per cent two-tail level in regressions 1 and 2, respectively. Furthermore, while neither of the partial regression coefficients of $\dot{K}$ in regression equations 3 and 4 are significant even at the 20 per cent two-tail level, both measures of research and development $R_{i}$ and $R_{k}$ are significant at the 1 per cent two-tail level. Finally, regressions 5 and 6 include, in addition to research and development measures, average plant and equipment $K$ and percentage net addition to gross plant and equipment $\dot{K}$.

Comparison of regressions 1 and 2 with 5 and of 3 and 4 with 6 reveals that the results do not change when $K$ and $\dot{K}$ are simultaneously present in the regression equations. Therefore, the independent variable, research and development, not only yields statistically significant results; it also accounts for practically all the explained variance of the dependent variable. That is, the additional independent variables 
TABLE 11

Multiple Regressions of the Rate of Growth of Productivity on Research and Development and Economies of Scale Variables Contained in Table 10, Chemical Firms

\begin{tabular}{|c|c|c|c|c|c|}
\hline \multirow{2}{*}{$\begin{array}{c}\text { Regression } \\
\text { Number and } \\
\text { Dependent } \\
\text { Variable }\end{array}$} & \multicolumn{4}{|c|}{ Independent Variable } & \multirow[b]{2}{*}{$\mathbf{R}^{2}$} \\
\hline & $R_{i}$ & $R_{k}$ & $K$ & $\dot{K}$ & \\
\hline (1) $\dot{P}$ & $\begin{array}{c}0.253 \\
(0.046) \\
0.668\end{array}$ & & $\begin{array}{c}(-) 0.001 \\
(0.004) \\
0.009\end{array}$ & & 0.671 \\
\hline (2) $\dot{P}$ & & $\begin{array}{c}0.296 \\
(0.044) \\
0.747\end{array}$ & $\begin{array}{c}0.003 \\
(0.003) \\
0.055\end{array}$ & & 0.749 \\
\hline (3) $\dot{P}$ & $\begin{array}{c}0.244 \\
(0.046) \\
0.654\end{array}$ & & & $\begin{array}{c}(-) 0.001 \\
(0.002) \\
0.028\end{array}$ & 0.677 \\
\hline (4) $P$ & & $\begin{array}{c}0.306 \\
(0.049) \\
0.722\end{array}$ & & $\begin{array}{c}0.001 \\
(0.002) \\
0.024\end{array}$ & 0.741 \\
\hline (5) $\dot{P}$ & & $\begin{array}{c}0.305 \\
(0.050) \\
0.730\end{array}$ & $\begin{array}{c}0.003 \\
(0.003) \\
0.047\end{array}$ & $\begin{array}{c}0.001 \\
(0.002) \\
0.017\end{array}$ & 0.753 \\
\hline (6) $\dot{P}$ & $\begin{array}{c}0.247 \\
(0.049) \\
0.649\end{array}$ & & $\begin{array}{c}(-) 0.001 \\
(0.004) \\
0.004\end{array}$ & $\begin{array}{c}(-) 0.001 \\
(0.002) \\
0.023\end{array}$ & 0.679 \\
\hline
\end{tabular}

See Table 10 for definitions of the variables.

See Table 7 for a description of the manner in which results are presented.

have not increased the total explanation significantly. This can be seen by examining the partial coefficients of determination of these additional independent variables, or by examining the simple $r^{2}$ 's in conjunction with the multiple coefficients of determination. ${ }^{23}$

The choice of the value added rather than the gross output measure was justified in the preceding section. Although, a priori, we should expect a less satisfactory relationship using gross output, it is still interesting to see the effect on the main results. Tables 12 and 13 contain the results of simple and multiple regressions of the rate of

${ }^{23}$ Minasian, op. cit., App. II contains similar multiple regression results for a subset of 1947-57 where research and development is lagged by three years. The results, in terms of partial coefficients of determination, for research and development are similar to those discussed in the section on profitability above; the lagged relationships offer less explanation, however, see discussion presented there. $\dot{K}$ performs similarly to the results in the text, but $K$ improves, has a negative sign, and is not significant. 
TABLE 12

Simple $r^{2}$ 's of the Rate of Growth of Productivity $\left(\dot{P}^{* * * *}\right)$, Average Research and Development Deflated by a Weighted Average of Total InPUTS, 1947-56 $\left(R_{i}\right)$, Average Research and Development Deflated by Real Gross Plant and Equipment, 1947-56 $\left(R_{k}\right)$, Average Gross Plant and Equipment, 1947-56 $(K)$, and Percentage Net additions to Gross Plant and Equipment, 1947-56 $(\dot{K})$, CHEMICAL FirmS

\begin{tabular}{lccrr}
\hline & $R_{i}$ & $R_{k}$ & $K$ & \multicolumn{1}{c}{$\dot{K}$} \\
\hline$\dot{P}^{* * * *}$ & 0.18 & 0.13 & 0.02 & 0.02 \\
$R_{i}$ & & 0.74 & 0.03 & $(-) 0.04$ \\
$R_{k}$ & & & $(-) 0.00$ & $(-) 0.15$ \\
$K$ & & & & 0.02 \\
\hline
\end{tabular}

See Table 10 for definitions of variables $\left(R_{i}\right),\left(R_{k}\right),(K)$, and $(\dot{K})$.

$\dot{P}^{* * * *}=$ Rate of growth in productivity (using output), equation (12).

TABLE 13

Multiple Regressions of the Rate of Growth of Productivity (USING outPut) ON Research and Development and EConomies of Scale Variables

Contained in Table 12, Chemical Firms

\begin{tabular}{|c|c|c|c|c|c|}
\hline \multirow{2}{*}{$\begin{array}{c}\text { Regression } \\
\text { Number and } \\
\text { Dependent } \\
\text { Variable }\end{array}$} & \multicolumn{4}{|c|}{ Independent Variable } & \multirow[b]{2}{*}{$R^{2}$} \\
\hline & $\boldsymbol{R}_{\boldsymbol{i}}$ & $R_{k}$ & $\boldsymbol{K}$ & $\dot{K}$ & \\
\hline (1) $\dot{P}^{* * * *}$ & $\begin{array}{c}0.129 \\
(0.068) \\
0.205\end{array}$ & & $\begin{array}{c}0.001 \\
(0.005) \\
0.001\end{array}$ & $\begin{array}{c}0.003 \\
(0.003) \\
0.061\end{array}$ & 0.235 \\
\hline (2) $\dot{P}^{* * * *}$ & & $\begin{array}{c}0.154 \\
(0.079) \\
0.214\end{array}$ & $\begin{array}{c}0.003 \\
(0.005) \\
0.018\end{array}$ & $\begin{array}{c}0.004 \\
(0.003) \\
0.099\end{array}$ & 0.244 \\
\hline
\end{tabular}

See Table 12 for definitions of the variables.

growth in productivity, based on output $\dot{P}^{* * * *}$, on average gross plant and equipment $K$, the percentage net additions to gross plant and equipment $\dot{K}$, and the two measures of research and development, $R_{i}$ and $R_{k}$.

Comparison of the first rows of the Tables 10 and 12 indicates the differences in the $r^{2}$ 's when the dependent variable uses value added and output, respectively. It can be seen that the $r^{2}$ 's of average gross plant and equipment $K$ and percentage net additions to gross plant and equipment $\dot{K}$ are approximately the same with both measures of productivity, i.e. nearly zero. However, the $r^{2}$ 's for both measures of research and development and the rate of growth in productivity are substantially larger when the dependent variable is derived from value 
added than from output, as is expected. They are 0.67 and 0.73 using value added but become 0.18 and 0.13 , respectively, when the rate of growth in productivity is measured by output.

Comparison of the multiple regression equations in Tables 11 and 13 reveals that, in terms of the partial coefficients of determination, the variables size and the percentage change in size perform a little better where the dependent variable uses output rather than value added. However, neither partial regression coefficient is significant at the 10 per cent two-tail level. Furthermore, both measures of research and development have partial regression coefficients barely significant at the 5 per cent two-tail level. But, in terms of partial coefficients of determination, they explain much less when the dependent variable uses output than when it uses value added. Finally, the multiple coefficients of determination are much smaller when output rather than value added is used.

We can conclude, therefore, that the main findings using value added are somewhat reinforced when output is used. However, we have a much stronger relationship in the former than in the latter case, in the level of significance of both the partial regression coefficients and the multiple and partial coefficients of determination.

We have so far analyzed firms in the chemical industry. We can not, unfortunately, do the same with the pharmaceutical firms since there are only five included in the sample. Since we have but three degrees of freedom at most, no correlations or regressions were computed. Scatter diagrams of some of the most important relationships were investigated. It is not an exaggeration to state that the findings seem to be compatible with those obtained above, with the case of returns to scale being an exception. It should, however, be emphasized that such inferences about the pharmaceutical firms are based upon the assumption that the pattern would remain the same if the sample size were increased; therefore they are highly tentative. ${ }^{24}$

\section{ALTERNATIVE HYPOTHESIS, MONOPOLY PRICING}

It will be recalled that our measures of value added and output are deflated to convert them to real terms. The effect of monopoly pricing on the deflation should be made clear. When a firm introduces a new product at a monopoly price, our price index (used for deflation) may not be affected, but our output and value added measures will be inflated. Thus our productivity estimate for that year may be an over-

${ }^{24}$ Ibid., pp. 50-53. 
statement. Now if the firm loses its monopoly on this product over time, value added will fall relative to the price index, pushing the productivity measure down.

It should be recognized that when a new product is introduced in a given year, the price index of that year is not affected, whether this product is included in the price index or not. However, if the product has been linked into the price index and its price changes in subsequent years, the price index will be affected. The extent of the change depends on the relative weight attached to the product in the index. We will consider three cases of this pricing effect on our measure of productivity to bring out the general type of result likely to be obtained.

The first case is when a new product is introduced and maintained indefinitely at a price higher than the long run competitive market price. Our measure of productivity for that year, when the price index is used to deflate the output or value added of the firm, will reflect the following influences. Since the price index is unaffected by the new product, the productivity measure for the firm involved will show an increase in the initial year which will be maintained indefinitely. The extent of the increase will depend on the relative portion of output represented by this new product and the extent to which the price of this product exceeds the competitive price. The productivity measure for the firms which did not participate in the production of the new product will be unaltered by that product, if it is not an input for older products.

The second case occurs when a new product is introduced by a firm (or firms) at a competitive market price. Under this circumstance, assuming the same input-output relation for the new and old products and assuming that the general price index represents competitive prices, the firms' measure of productivity also will be unaltered by this development.

Case three involves a new product priced monopolistically at first but competitively later, and linked into the price index. When the price of the new product decreases to a competitive level, the price index will decline accordingly. In the first year the effects are identical to case one above. In the following years, the productivity measure for firm(s) enjoying temporary monopoly power over the new product will decrease and that for firms which are not involved with producing the new product will increase. These results hold strictly, if some firms produce the new product only and the rest produce only the old. 
In reality, we have more than one product introduced during this period by all firms, which complicates the situation. If we assume that the new products are priced monopolistically when they are introduced but approach competitive prices as time goes on, the crucial question is whether, during the period in question, the firms have gained more in monopoly power through the introduction of new products than they have lost through competition in the market on products previously introduced. This depends on the following conditions: (1) The proportion of total output or value added devoted to new products each year; (2) The time lapse, if any, between the introduction of the new product and the loss of monopoly power; (3) The extent to which the price charged by the firm exceeds the competitive price; (4) The relative weights attached to new and old products in both the general and the firms' own price indexes.

It can be seen that the more intense the conditions postulated under 1,2 , and 3 above are, the more the rate of growth in the measure of productivity reflects monopoly pricing. However, the effect of condition 4 works both ways. If the general price index links new products as they are introduced into the market, if these new products are introduced at monopoly prices but tend toward competitive ones over time, and if the extent of monopoly power is constant ( 3 , above) the general price index will have a downward bias for the purpose of deflating value added. This downward bias will be constant over time-affecting all the observations on productivity for all years by a constant; thus not affecting the slope, i.e. the rate of growth of productivity -if the net rate of gain in monopoly power (gain on new products minus the loss on previously introduced products) is zero for each firm. Therefore, our estimates of $\dot{P}$ for any firm will be affected by monopoly pricing if there is a net change in monopoly power. For example, if some firms gain in monopoly power and some lose so that the average is unchanged, over time the bias of the general price index will increase for the former and decrease for the latter. If new products are introduced into the index at competitive prices, the productivity measure will be affected only by changing monopoly power over time (condition (3) above).

Two chemical firms indicated the percentage of their annual sales arising from new products. For the years that we have these data, no trend over time in these percentages is apparent. Furthermore, these percentages are in the order of magnitude of 3 to 5 per cent. 35 per cent of the 1958 sales of three firms were for products introduced since 
1945. One of these three firms provided its own weighted average price index, using relative quantities of products sold as weights. We computed the rate of growth in productivity of this firm using its own price index and compared it with the one based on our estimated price index. The two measures of $\dot{P}$ obtained had a ratio of the order of 1.05. $P$ based on our estimated price index was used in the regressions. Two other firms supplied their own price indexes for a few years. There was a very close correspondence in both the absolute change and the direction of change between these and the price indexes estimated for these firms.

Finally, the weighted price indexes constructed for each of the chemical firms were ranked according to the extent of the increase between 1947 and 1957. The smallest range was from 100 in 1947-49 to 85 in 1957 and the highest from 100 in 1947-49 to 141 by the end of the period. Spearman rank correlation between the rate of growth in productivity and the percentage change in the price indexes during 1947-57, assigning the lowest rank to the smallest percentage change, had a simple coefficient of determination of $(-) 0.04$ which is not significant at the 35 per cent two-tail or the 75 per cent one-tail level. Therefore, our price indexes cannot be the cause of such correlation.

Considering the evidence given in this section, it seems that monopolistic pricing has not affected our measure of the rate of growth in productivity so much as to make the latter primarily a measure of changes in monopoly power. Nevertheless, we cannot presume that this disposes of the problem.

We are interested in finding a variable which will reflect the effects of idiosyncrasies in price changes in general and in monopoly prices in particular, and then in using it as another independent variable to explain the rate of growth in productivity. A plausible candidate for such a variable is the trend in the profitability of a firm over time. Since it depends on changes in supply and demand conditions and on the pattern of monopoly prices, the trend of profitability will be affected to a different extent if the rates of losses or gains of monopoly power are different among firms. ${ }^{25}$ Profitability is defined as net profits

\footnotetext{
${ }^{25}$ Note that the role of the trend of profitability as an independent variable will not be affected whether it is taken relative to a competitive industry or an average for the economy, since we will be in essence subtracting or dividing (depending on how the deviations are expressed) the variable by a constant. Furthermore, the general behavior of the economy during 1947-57 will affect the firms differently depending on the shapes of their cost curves which are not identical at least because of differences in monopoly position.
} 
after taxes (adjusted for other financial income and expenses, i.e., dividends received and paid), plus interest payments deflated by the implicit price deflator of GNP divided by gross plant and equipment. ${ }^{26}$

The reason for adding the trend of profitability to a multiple regression equation as an independent variable when the rate of growth in productivity is the dependent variable should be made clear. The trend of profitability does not belong in the regression equation as an explanatory variable if our measure of the rate of growth in productivity does not reflect idiosyncrasies of price changes, since, a priori, the chain of causation runs from productivity to profitability. However, we want to test for the effect of possible idiosyncrasies of price changes on our measure of productivity. Therefore, if the dependent variable is affected by such price changes, the trend of profitability belongs in a multiple regression equation if it also reflects the price changes which, by assumption, have not been eliminated by the price indexes used.

The regression results are summarized in Tables 14 and 15. The $r^{2}$ between the trend of profitability $\dot{I}$ and the rate of growth in productivity $\dot{P}$ is 0.60 , and the $r^{2}$ 's between $\dot{I}$ and the two measures of research and development $R_{i}$ and $R_{k}$ are respectively 0.30 and 0.46 . Furthermore, the $r^{2}$ 's of $\dot{I}$ with $K$ and $\dot{K}$ are 0.00 and (-)0.06, respectively, which are not significantly different from zero at the 10 per cent two-tail level.

Multiple regression equation 3 utilizes $K, \dot{K}$, and $\dot{I}$ as independent variables. The partial regression coefficients of $K$ and $\dot{K}$ are not significant at even the 10 per cent two-tail level. However, the partial regression coefficient of $\dot{I}$ is significant at the 1 per cent two-tail level. In terms of the partial coefficient of determination, the trend of profitability explains 57 per cent of the variation in the rate of growth of productivity.

Multiple regression equations 4 and 5 contain, besides $K$ and $\dot{K}$, both variables $I$ and $R_{i}$ (and alternatively $R_{k}$ ) as independent variables. Partial regression coefficients of $I$ are significant at the 1 per cent twotail level in both regressions 4 and 5. Both measures $R_{i}$ and $R_{k}$ obtain

${ }^{26}$ A more accurate concept of profitability would use as its base all of the capital of the firm rather than just gross plant and equipment. Using an all-inclusive concept of capital will yield different results if the time paths of net plant and equipment, inventories, cash, etc., are dissimilar among the firms. Such a measure was developed and used in place of gross plant and equipment. It is to be noted that the conclusions arrived at in this section are supported by the alternative measure of capital stock, as the levels of significance are similar. See Minasian, op. cit., App. III, for the construction of the measure and the results of the regressions. 
TABLE 14

Simple $r^{2}$ 's of the Rate of Growth of Productivity $(\not \vec{P})$, Average Research and Development Deflated by a Weighted Average of Total InPUTS, 1947-56 $\left(R_{i}\right)$, Average Research and Development Deflated by Real Gross Plant and Equipment, 1947-56 $\left(\boldsymbol{R}_{k}\right)$, Average Gross Plant and Equipment, 1947-56 (K), Percentage Net Additions to Gross Plant and Equipment, 1947-56

$(\dot{K})$, and the Trend of Profitability, 1947-57 ( $I$ ), Chemical Firms

\begin{tabular}{lcrrrr}
\hline \hline & $K$ & $\dot{K}$ & \multicolumn{1}{c}{$I$} & \multicolumn{1}{c}{$R_{i}$} & \multicolumn{1}{c}{$R_{k}$} \\
\hline$\dot{P}$ & 0.01 & $(-) 0.07$ & 0.60 & 0.67 & 0.73 \\
$K$ & & 0.02 & 0.00 & 0.03 & $(-) 0.00$ \\
$\dot{K}$ & & & $(-) 0.06$ & $(-) 0.04$ & $(-) 0.15$ \\
$I$ & & & & 0.30 & 0.46 \\
$R_{i}$ & & & & & 0.74 \\
\hline
\end{tabular}

See Table 10 for definitions of variables $(P),\left(R_{i}\right),\left(R_{k}\right),(K)$, and $(\dot{K})$.

(Net income after taxes+interest payments + adjustments-as before) ${ }_{t}$

$$
I_{t}=\frac{\text { deflated by the GNP implicit price deflator }^{\text {(Real gross plant and equipment })_{t}}}{\text { (R) }}
$$

$=$ The profitability in year $t$.

The trend of profitability for an individual firm is obtained by regressing $\log e I_{t} / I_{\text {o }}$ on time. That is:

$$
\frac{I_{t}}{I_{0}}=C e^{r t}
$$

where $r$ is the slope of the regression line and the trend of the profitability. $I_{0}$ is the value of $I$ in 1947.

partial regression coefficients significant at the 1 per cent two-tail level in regressions 4 and 5 . In terms of partial coefficients of determination, $I$ explains 46 per cent of the variation in the rate of growth in productivity in regression 4 and 25 per cent of the variation in regression 5 , while the research and development measures $R_{i}$ and $R_{k}$ explain, respectively, 55 per cent and 53 per cent of the variation in regressions 4 and 5.

What do these results mean? First, it is apparent that both measures of research and development are stronger independent variables than the trend of profitability. Second, if both variables, the rate of growth in productivity and the trend of profitability, were purely the by-products of idiosyncrasies of price changes, the measure of research and development would have become a statistically insignificant independent variable. Third, if idiosyncratic price changes were the result of changes in monopoly pricing power and if research and development represented this effect better than the trend of profitability, then both independent variables would summarize the same effects, and either the weaker one would become statistically insigni- 
ficant or, if they were equally strong, the regression coefficient of both would become insignificant.

TABLE 15

Multiple Regressions of the Rate of Growth of Productivity on Research and Development, Economies of SCale, and Monopoly Pricing Variables Contained in Table 14, Chemical Firms

\begin{tabular}{|c|c|c|c|c|c|c|}
\hline \multirow{2}{*}{$\begin{array}{c}\text { Regression } \\
\text { Number and } \\
\text { Dependent } \\
\text { Variable }\end{array}$} & \multicolumn{5}{|c|}{ Independent Variable } & \multirow[b]{2}{*}{$\mathbf{R}^{2}$} \\
\hline & $K$ & $\dot{K}$ & $t$ & $R_{i}$ & $R_{k}$ & \\
\hline (1) $\dot{P}$ & $\begin{array}{c}0.003 \\
(0.003) \\
0.047\end{array}$ & $\begin{array}{c}0.001 \\
(0.002) \\
0.017\end{array}$ & & & $\begin{array}{c}0.305 \\
(0.050) \\
0.730\end{array}$ & 0.753 \\
\hline (2) $P$ & $\begin{array}{c}(-) 0.001 \\
(0.004) \\
0.004\end{array}$ & $\begin{array}{c}(-) 0.001 \\
(0.002) \\
0.023\end{array}$ & & $\begin{array}{c}0.247 \\
(0.049) \\
0.649\end{array}$ & & 0.679 \\
\hline (3) $\dot{P}$ & $\begin{array}{c}0.001 \\
(0.004) \\
0.009\end{array}$ & $\begin{array}{c}(-) 0.001 \\
(0.002) \\
0.018\end{array}$ & $\begin{array}{c}0.189 \\
(0.044) \\
0.574\end{array}$ & & & 0.611 \\
\hline (4) $\dot{P}$ & $\begin{array}{c}0.002 \\
(0.003) \\
0.035\end{array}$ & $\begin{array}{c}0.001 \\
(0.002) \\
0.018\end{array}$ & $\begin{array}{c}0.087 \\
(0.041) \\
0.252\end{array}$ & & $\begin{array}{c}0.224 \\
(0.059) \\
0.526\end{array}$ & 0.815 \\
\hline (5) $P$ & $\begin{array}{c}(-) 0.001 \\
(0.003) \\
0.006\end{array}$ & $\begin{array}{c}(-) 0.000 \\
(0.002) \\
0.005\end{array}$ & $\begin{array}{c}0.117 \\
(0.035) \\
0.457\end{array}$ & $\begin{array}{c}0.173 \\
(0.043) \\
0.552\end{array}$ & & 0.825 \\
\hline
\end{tabular}

See Table 14 for definitions of the variables.

See Table 7 for a description of the manner in which results are presented.

We have, however, a result where both independent variables are statistically significant. It seems that two interpretations could rationalize the result.

One, the rate of growth in productivity and the trend of profitability are positively correlated since each is affected by the idiosyncrasies of price changes. Thus, to the extent that the rate of growth in productivity is attributable to such uncorrected price changes, an indication of this effect is given by the partial regression coefficient of the trend of the profitability variable. Therefore, under this interpretation, the role of this variable in the regression equation is that of correcting our measure of productivity.

Two, there will be a significant positive correlation between the trend of profitability and the rate of growth in productivity, so long as there are other forces affecting the trend which are not summarized 
by research and development. Factor(s) of production specific to the firm, such as differential entrepreneurial capacity, may be such forces. Furthermore, there are efficiencies obtained from better organization and there are also changes which take place continuously on the production line. To the extent, however, that these changes are obtained through either research and development directly or through other variables for which research and development is an instrumental variable, we have accounted for such forces. However, there is no a priori reason to believe that such is the case. Thus, productivity and profitability may be affected by some types of change independent of research and development, and thus be correlated in the regression beyond their correlation with research and development.

The significant positive correlation between the rate of growth in productivity and the trend of profitability is not prima facie evidence of the existence of idiosyncrasies of price changes-differential behavior of monopoly pricing being a facet-in our productivity measures. However, even if we interpret the results as a case for the existence of such an effect, we see that there is substantial variance in the dependent variable left unexplained by the variable, the trend of profitability.

We can summarize the results of this section to this point thus: we can not conclude whether the significance of the trend of the profitability variable is due to the differential behavior of monopoly power over the period, or to other factors which may have affected both the rates of growth in productivity and the trend values not summarized by the research and development variable.

It should be emphasized that this trend variable at best tests for the changes in monopoly power in the period only. It does not test the level of monopoly power in the industry. If the monopoly power, regardless of how strong it was, had stayed constant, the rates of growth of productivity variables would be immune from errors caused by monopoly considerations. All the observations on productivity for a firm for all years will be inflated or deflated by a constant which, of course, does not affect the slope-the rate of growth of productivity.

\section{RETURNS TO RESEARCH AND DEVELOPMENT EXPENDITURES}

Under the "profitability" hypothesis, we saw that lagged research and development explained end-of-period profitability better than vice versa; this suggests that research and development does affect 
profitability. The logical question, then, is: does research and development explain not only differences in levels of profitability but also differences in profitability time paths among firms ? ${ }^{27}$ Strictly speaking, a positive correlation between research and development and the rate of growth in productivity does not imply a positive correlation between research and development and the trend of profitability, since the latter will depend crucially on the industrial organization and the lags in adjustment to a change in the system. Therefore, we may look at the degree of correlation as an indication either of type of industrial organization or of lags of adjustment present in the industry (see, however, footnote 27).

The dependent variable of our analysis now becomes the trend of profitability $\dot{I}$. The simple coefficients of determination are those given in Table 14. The results of the multiple regression equations are given in Table 16. Average gross plant and equipment $K$ and percentage net additions to gross plant and equipment $\dot{K}$ are utilized as independent variables in regressions (1) through (5). It can be seen that neither variable is significant even at the 10 per cent two-tail level in any of the multiple regressions. The highest partial coefficients of determination for $K$ and $\dot{K}$ are, respectively, 1 per cent and 2 per cent regressions 1 and 2.

Regressions 1 and 2 contain two alternative measures of research and development, $R_{i}$ and $R_{k}$. Both partial regression coefficients are significant at even the 1 per cent two-tail level. In terms of partial coefficients of determination, $R_{k}$ and $R_{i}$ explain approximately 43 per cent and 27 per cent of the variation in the dependent variable, respectively.

The above results indicate that the larger the research and development effort the greater the trend (value) in profitability. Strictly speaking, the profitability of all firms but four decreased over time. Therefore, if we think of the highest absolute trend value as zero, the above statement is true. Otherwise we have to restate the relationship in the following way: the larger the research and development the smaller the decrease in profitability. Furthermore, this result indicates that there exists a positive gross return to research and development expenditures.

Multiple regression technique may be used to shed some light on the

${ }^{27}$ To the extent that there are differences in research and development expenditures among firms and since investment in research and development is excluded from our capital base, there is some spurious correlation between research and development and the trend. 
TABLE 16

Multiple Regressions of the Trend of Profitability $(l)$ on Research and

Development, Economies of Scale, Monopoly Pricing, and the Rate of Growth of Productivity Variables Contained in Table 14,

Chemical Firms

\begin{tabular}{|c|c|c|c|c|c|c|}
\hline \multirow{2}{*}{$\begin{array}{c}\text { Regression } \\
\text { Number and } \\
\text { Dependent } \\
\text { Variable }\end{array}$} & \multicolumn{5}{|c|}{ Independent Variable } & \multirow[b]{2}{*}{$\mathbf{R}^{2}$} \\
\hline & $K$ & $\dot{K}$ & $\vec{P}$ & $\boldsymbol{R}_{\mathrm{i}}$ & $R_{k}$ & \\
\hline (1) $I$ & $\begin{array}{c}0.008 \\
(0.018) \\
0.012\end{array}$ & $\begin{array}{c}0.001 \\
(0.011) \\
0.000\end{array}$ & & & $\begin{array}{c}0.937 \\
(0.288) \\
0.431\end{array}$ & 0.470 \\
\hline (2) $I$ & $\begin{array}{c}(-) 0.001 \\
(0.021) \\
0.000\end{array}$ & $\begin{array}{c}(-) 0.007 \\
(0.012) \\
0.023\end{array}$ & & $\begin{array}{c}0.630 \\
(0.281) \\
0.265\end{array}$ & & 0.315 \\
\hline (3) $I$ & $\begin{array}{c}(-) 0.000 \\
(0.016) \\
0.000\end{array}$ & $\begin{array}{c}(-) 0.002 \\
(0.009) \\
0.004\end{array}$ & $\begin{array}{c}3.033 \\
(0.698) \\
0.574\end{array}$ & & & 0.603 \\
\hline (4) $I$ & $\begin{array}{c}(-) 0.000 \\
(0.017) \\
0.000\end{array}$ & $\begin{array}{c}(-) 0.002 \\
(0.010) \\
0.003\end{array}$ & $\begin{array}{c}2.916 \\
(1.393) \\
0.252\end{array}$ & & $\begin{array}{c}0.049 \\
(0.497) \\
0.001\end{array}$ & 0.603 \\
\hline (5) $I$ & $\begin{array}{c}0.002 \\
(0.016) \\
0.002\end{array}$ & $\begin{array}{c}(-) 0.002 \\
(0.009) \\
0.005\end{array}$ & $\begin{array}{c}3.911 \\
(1.184) \\
0.457\end{array}$ & $\begin{array}{c}(-) 0.334 \\
(0.362) \\
0.061\end{array}$ & & 0.627 \\
\hline
\end{tabular}

See Table 14 for definitions of the variables.

See Table 7 for a description of the manner in which results are presented.

direction of the effects. For example, in our problem, we are certain that research and development will affect profitability if it affects productivity. Thus when the trend of profitability is the dependent variable, we can look at research and development (independent variable) as an instrumental variable for the rate of growth of productivity. Therefore, when both research and development and the rate of growth of productivity are introduced into the multiple regression with the trend of profitability as the dependent variable, research and development should lose its explanatory power. We would expect this result so long as the simple coefficients of determination between the dependent and the two independent variables are not of approximately the same magnitude, and so long as the two independent variables do not have substantial correlation between them. In the latter case the matrix of variance covariance will become larger and larger tending to give statistically insignificant answers. Having this point 
in mind, let us examine the results of multiple regressions (3) through (5) in Table 16 above.

Multiple regression equation 3 contains the rate of growth in productivity $\dot{P}$ in addition to $K$ and $\dot{K}$. The variable $\dot{P}$ has a partial regression coefficient significant at even the 1 per cent two-tail level. Multiple regression equations 4 and 5 include $\dot{P}$ and $R_{i}$ and, alternatively $R_{k}$ as independent variables in addition to $K$ and $\dot{K}$. It can be seen that in both regressions the two alternative measures of research and development become statistically insignificant. However, the rate of growth in productivity has a partial regression coefficient significant at even the 1 per cent two-tail level in both regressions 4 and 5 .

This result is consistent with our belief that research and development affects profitability if the aforementioned conditions are present in the system, only by first affecting productivity.

\section{Conclusion}

We have seen that in no single test was the hypothesis advanced in this study disproved. The relevant research and development expenditure was found to be a highly significant independent variable explaining not only the rate of growth in productivity but also the trend of the profitability of eighteen chemical firms in the sample.

In hope of shedding some light on the chain of causality involved, we tested alternative hypotheses that increases in productivity might be explained by profitability or investment. Both hypotheses were rejected. Furthermore, investment in plant and equipment showed a consistent, but not statistically significant, negative correlation with investment in research and development. This suggests that the two types of investment are competitive rather than complementary in nature. We also found that lagged research and development explains end-of-period profitability better than end-of-period research and development is explained by lagged profitability; this suggests that research and development does affect profits.

We also investigated the relationship between the growth in productivity and the rate of change in output, average plant size and, essentially, the rate of growth in plant size. Nowhere did we find a statistically significant relationship. Once we eliminated the statistical illusion of size, we found that firms which spent relatively large sums on research and development were not typically large. In addition, these firms were the highest ranking in productivity gains. We did not 
find conclusive evidence to dispute the hypothesis that the differential behavior of monopoly power among firms over time may have affected our productivity measure.

We have seen that research and development expenditures explain, significantly, both the level and the trend of profitability. We have concluded that this result indicates that there are gross returns to research and development expenditures. However, the form of the function chosen does not lend itself to estimation of absolute magnitudes of net returns.

Finally, scatter diagrams were investigated for five firms in the drug and pharmaceutical industry. If the pattern of the results obtained for these five firms prevails as sample size increases, we can probably conclude that the above conclusions will also hold for drug and pharmaceutical firms with the exception of the findings about returns to scale.

What can we infer from our results? It will be recalled that the sample was strictly a nonrandom one. Therefore, our conclusions apply only to the firms in the sample; if the sample is representative our conclusions are applicable to the chemical industry. Because of differences among industries, it would be reckless to generalize these results to cover the entire economy (we have no information on relative innovating costs and returns for the latter). Further, all differentials in productivity should not be attributed to research and development expenditures, since these are by nature residuals and may well catch many irrelevant factors such as royalties paid. The test for the royalties hypothesis was inconclusive, perhaps because of poor data. Additional work in this direction may be useful. 
